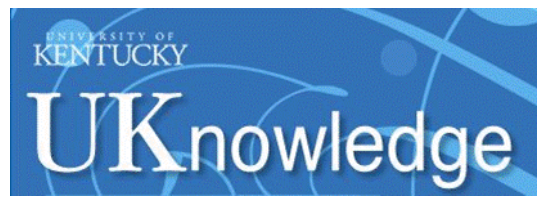

University of Kentucky

UKnowledge

\title{
Enhancements in Mass Transfer for Carbon Capture Solvents Part I: Homogeneous Catalyst
}

\author{
Leland R. Widger \\ University of Kentucky \\ Moushumi Sarma \\ University of Kentucky, moushumi.sarma@uky.edu \\ Jonathan J. Bryant \\ University of Kentucky \\ David S. Mannel \\ University of Kentucky, david.mannel@uky.edu \\ Jesse G. Thompson \\ University of Kentucky, jesse.thompson@uky.edu
}

See next page for additional authors

Follow this and additional works at: https://uknowledge.uky.edu/caer_facpub

Part of the Catalysis and Reaction Engineering Commons, and the Oil, Gas, and Energy Commons

Right click to open a feedback form in a new tab to let us know how this document benefits you.

\section{Repository Citation}

Widger, Leland R.; Sarma, Moushumi; Bryant, Jonathan J.; Mannel, David S.; Thompson, Jesse G.; Lippert, Cameron A.; and Liu, Kunlei, "Enhancements in Mass Transfer for Carbon Capture Solvents Part I: Homogeneous Catalyst" (2017). Center for Applied Energy Research Faculty and Staff Publications. 26. https://uknowledge.uky.edu/caer_facpub/26

This Article is brought to you for free and open access by the Center for Applied Energy Research at UKnowledge. It has been accepted for inclusion in Center for Applied Energy Research Faculty and Staff Publications by an authorized administrator of UKnowledge. For more information, please contact UKnowledge@lsv.uky.edu. 


\section{Enhancements in Mass Transfer for Carbon Capture Solvents Part I: Homogeneous Catalyst}

\section{Digital Object Identifier (DOI)}

https://doi.org/10.1016/j.ijggc.2017.05.019

\section{Notes/Citation Information}

Published in International Journal of Greenhouse Gas Control, v. 63, p. 249-259.

(c) 2017 Elsevier Ltd. All rights reserved.

This manuscript version is made available under the CC-BY-NC-ND 4.0 license https://creativecommons.org/licenses/by-nc-nd/4.0/.

The document available for download is the author's post-peer-review final draft of the article.

\section{Authors}

Leland R. Widger, Moushumi Sarma, Jonathan J. Bryant, David S. Mannel, Jesse G. Thompson, Cameron A. Lippert, and Kunlei Liu 
$5{ }^{1}$ Center for Applied Energy Research, 2540 Research Park Drive, University of Kentucky,

6 Lexington, KY 40511, United States

$7 \quad{ }^{2}$ Department of Mechanical Engineering, University of Kentucky, Lexington, KY 40506

8 *To whom correspondence should be addressed, Phone: +1 (859)-257-0293, Fax: +1 859-257-

9 0302, e-mail: Kunlei.Liu@uky.edu

\section{Abstract}

11 The novel small molecule carbonic anhydrase (CA) mimic $\left[\mathrm{Co}^{\mathrm{III}}\left(\mathrm{Salphen}_{\mathrm{COO}}\right)^{-} \mathrm{Cl}\right] \mathrm{HNEt}_{3}(\mathbf{1})$, 12 was synthesized as an additive for increasing $\mathrm{CO}_{2}$ absorption rates in amine-based post13 combustion carbon capture processes (CCS), and its efficacy was verified. 1 was designed for use 14 in a kinetically slow but thermally stable blended solvent, containing the primary amines 1-amino15 2-propanol (A2P) and 2-amino-2-methyl-1-propanol (AMP). Together, the A2P/AMP solvent and

17 relative to the baseline solvent MEA. 1 is also effective at increasing absorption kinetics of 18 kinetically fast solvents, such as MEA, which can reduce capital costs by requiring a smaller 19 absorber tower. The transition from catalyst testing under idealized laboratory conditions, to 20 process relevant lab- and bench-scale testing adds many additional variables that are not well 21 understood and rarely discussed. The stepwise testing of both $\mathbf{1}$ and the novel A2P/AMP solvent 22 blend is described through a transition process that identifies many of these process and evaluation 
1 challenges not often addressed when designing a chemical or catalytic additive for industrial CCS

2 systems, where consideration of solvent chemistry is typically the primary goal.

3 Keywords: Post-combustion; $\mathrm{CO}_{2}$ capture; Mass transfer; Amine; Catalyst; Additives.

\section{Introduction}

5 Increasing concern over global $\mathrm{CO}_{2}$ emissions has led to new regulations from the US

6 Environmental Protection Agency (EPA) for coal-fired power generation, which is responsible for

7 the emission of billions of tons annually. As of January 2014, new coal burning units require

8 carbon capture and storage (CCS) processes to reduce $\mathrm{CO}_{2}$ emissions to $1100 \mathrm{lb} / \mathrm{MW} .{ }^{1}$ Amine-

9 based carbon capture is the most widely studied, and most likely to be implemented commercially,

10 method for $\mathrm{CO}_{2}$ purification from flue gas. ${ }^{2}$ However, the cost of these systems is still prohibitive,

11 and reduction in both capital and operational costs, relative to the Department of Energy (DOE)

12 reference case $12,30 \mathrm{wt} . \%$ monoethanolamine (MEA), is necessary. ${ }^{3}$ In general, capital costs arise

13 on the absorption side of the process, while operational costs arise on the $\mathrm{CO}_{2}$ stripping/solvent

14 regeneration side. Construction of the absorption tower (absorber) alone accounts for

15 approximately $20 \%$ of the initial capital investment for construction of a carbon capture system;

16 therefore significant effort has focused on understanding and increasing absorption kinetics of the

17 amine solvent in the absorption tower., ${ }^{2,-7}$

Research toward increasing $\mathrm{CO}_{2}$ absorption in solvent-based CCS processes has focused on three main strategies: (1) solvent development/amine blends, ${ }^{8-14}$ (2) modification of the packing material to increase wetted surface area, ${ }^{15-16}$ and (3) the addition of catalysts, such as small-molecule carbonic anhydrase (CA) mimics, ${ }^{17-20}$ to increase the chemical kinetics of absorption and desorption ${ }^{21}$ reactions. The development of new amines and solvent blends has been delivering 
1 incremental gains, as there is always a tradeoff between reactivity and stability, where increased

2 absorption kinetics is generally associated with higher regeneration energy and reboiler duty. ${ }^{22-23}$

3 In addition, the emission of amine degradation products, ${ }^{24-25}$ particularly carcinogenic

4 nitrosamines from secondary amine solvents, ${ }^{26}$ rises concerns over the use of some potentially

5 effective absorption solvents. Absorption catalyst development has also been plagued with process

6 difficulties, and the most widely studied (1) carbonic anhydrase (CA), and (2) the CA mimic,

$7 \quad\left[\mathrm{Zn}(\right.$ cyclen $\left.)\left(\mathrm{H}_{2} \mathrm{O}\right)\right]\left(\mathrm{ClO}_{4}\right)_{2}$, are ineffective under CCS conditions. ${ }^{27,22}$

8 Recent work has led to the first reported examples of homogenous $\mathrm{CO}_{2}$ hydration catalysts that

9 allowed for mass transfer enhancement in kinetically-fast primary amine solvents. ${ }^{27-29}$ These

10 catalysts incorporate electron donating ligand environments and ionic secondary coordination

11 sphere groups to increase solubility in aqueous solutions, promote $\mathrm{CO}_{2}$ hydration, and facilitate

12 bicarbonate dissociation away from the metal center. Previous reports have detailed the synthesis,

13 characterization, and preliminary laboratory testing of these catalysts under conditions conducive

14 to carbon capture processes, i.e. low $\mathrm{CO}_{2}$ concentration $(0.14 \mathrm{~atm})$, and high amine concentration

15 (5 M). These previously reported complexes were shown to be stable toward the high temperatures

16 (up to $145^{\circ} \mathrm{C}$ ) and oxidizing flue gas contaminants $\left(\mathrm{SO}_{\mathrm{x}}\right.$ and $\left.\mathrm{NO}_{\mathrm{x}}\right)$ associated with industrial CCS

17 processes. Herein we report the testing and analysis of the novel catalyst $\left[\mathrm{Co}^{\mathrm{III}}\left(\mathrm{Salphen}_{-} \mathrm{COO}^{-}\right.\right.$

$18 \mathrm{Cl}_{\mathrm{HNEt}}(\mathbf{1})$, and describe the difficulties associated with integrating the new additive into a

19 bench scale, heat-integrated absorber-stripper process.

\section{Experimental}

21 2.1. General. Reagents for solvent mixtures, catalyst synthesis, and kinetics studies were

22 purchased from Sigma Aldrich, monoethanolamine was purchased from Univar. Solutions of 23 monoethanolamine (MEA, $5 \mathrm{M})$ and the A2P/AMP blended solvent $(0-30$ wt. $\%$ of each 
1 component) were prepared by weight $\%$ and adjusted to an alkalinity of $5.0 \mathrm{~mol} \mathrm{~N} / \mathrm{Kg}$.

2 Experimental methods for $\mathrm{pH}$ drop, ${ }^{27,}{ }^{30}$ total inorganic carbon loading, ${ }^{31}$ and alkalinity ${ }^{31}$

3 measurements were conducted according to reported procedures. The surface tension and the

4 surface elasticity data were acquired at $22{ }^{\circ} \mathrm{C}$ on a Biolin Scientific Optical Tensiometer, using

5 Oneattension software. The viscosity of the solutions were determined by using the Brookfield

6 DVI viscometer. Catalyst loading of $2.3 \mathrm{~g} / \mathrm{L}$ is used based on previously reported studies. ${ }^{28-29}$

7 Foaming volume measurements were conducted in a $100 \mathrm{~mL}$ graduated cylinder, with $10 \mathrm{~mL}$ of

8 solvent, under study. Simulated flue gas $\left(14 \% \mathrm{CO}_{2}\right.$ with balance $\left.\mathrm{N}_{2}\right)$ gas was purged through a gas

9 impinger at a constant flow rate $(0.6 \mathrm{~L} / \mathrm{min})$. The volume of the foam formed with continuous

10 purging of $\mathrm{CO}_{2}$ was then recorded as a function of time.

11 2.2. Synthesis of $\left[\mathrm{Co}^{\mathrm{III}}(\right.$ Salphen-COO-)CI]HNEt 3 (1). N,N'-disalicylidene-4-carboxy-1,2-

12 phenylenediamine (Salphen-COOH) ${ }^{32}$ was synthesized by stirring salicylaldehyde $(1.80 \mathrm{~mL}, 16.9$

$13 \mathrm{mmol})$ and 3,4-diamino benzoic acid $(1.01 \mathrm{~g}, 6.5 \mathrm{mmol})$ in ethanol $(40 \mathrm{~mL})$ overnight, then

14 collecting the orange solid ( $2.05 \mathrm{~g}, 86 \%$ yield) by filtration and washing with ethanol and diethyl

15 ether. The Salphen-COOH ligand was suspended in ethanol $(30 \mathrm{~mL})$, followed by addition of

16 triethylamine $(2.80 \mathrm{~mL}, 20.1 \mathrm{mmol})$. An ethanolic $(30 \mathrm{~mL})$ solution of $\mathrm{CoCl}_{2} \bullet 6 \mathrm{H}_{2} \mathrm{O}(1.49 \mathrm{~g}, 6.2$

$17 \mathrm{mmol}$ ) was added to the reaction mixture drop wise over $15 \mathrm{~min}$ to give dark brown solution, and

18 the reaction mixture was stirred overnight at room temperature. Diethyl ether $(50 \mathrm{~mL})$ was added,

19 and the resulting brown precipitate was collected by vacuum filtration. The solid product was

20 washed with methanol $(30 \mathrm{~mL})$, diethyl ether $(30 \mathrm{~mL})$, and allowed to air dry, giving $1(3.07 \mathrm{~g}$,

$2193 \%$ ) as a brown powder. FTIR-ATR $\left(\mathrm{cm}^{-1}\right): 3369$ (s), 2979 (m), 1601 (vs, C=N), 1539 (s), 1442

22 (s), 1369(s), 1304(s), 1151(s). ESI-ToF (m/z): $417.02777\left[\mathbf{1}-\mathrm{Et}_{3} \mathrm{~N}-\mathrm{Cl}\right]^{+}$. Elemental analysis [1 
$2 \mathrm{~N}, 6.82$.

3

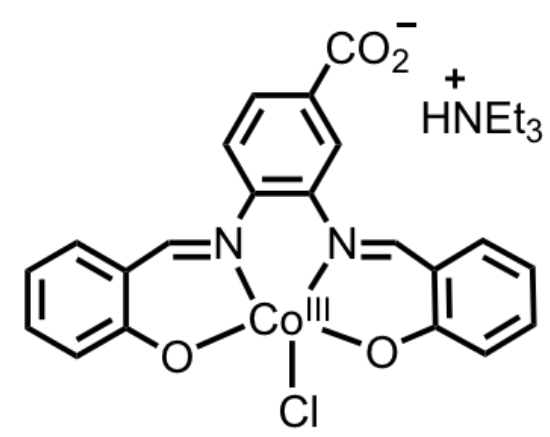

Figure 1. Proposed structure of $\mathbf{1 .}$

2.3. Breakthrough Solvent Evaluation Apparatus: Breakthrough experiments were conducted as previously reported. ${ }^{27,} 29$ In a representative procedure, the breakthrough solvent evaluation apparatus (Figure 2) consists of a $30 \mathrm{ml}$ gas saturator, a $30 \mathrm{ml}$ bubbler, a condenser, and a $\mathrm{CO}_{2}$ analyzer. Both the saturator and the bubbler are made of Pyrex ${ }^{\circledR}$, and are immersed in a water bath maintained at $40{ }^{\circ} \mathrm{C}$. $\mathrm{A} \mathrm{CO}_{2}$ feed gas stream (12\%-14\%) balanced with $\mathrm{N}_{2}$ is saturated with water in the saturator and bubbled through a $30 \mathrm{wt} \%$ MEA solution in the bubbler $(1 \mathrm{~L} / \mathrm{min})$. The gas effluent is dried over drierite and analyzed for $\mathrm{CO}_{2}$ concentration (vol\%) using a $\mathrm{CO}_{2}$ analyzer (VIA-510, HORIBA, $0.5 \%$ precision). Data of $\mathrm{CO}_{2}$ outlet concentration with respect to time is continuously recorded with 1 second interval using an in-house Labview program.

The difference of inlet and outlet $\mathrm{CO}_{2}$ concentration represents the absorbed amount of $\mathrm{CO}_{2}$ at a particular time. The integration of the concentration difference represents the $\mathrm{CO}_{2}$ loading, as expressed in equation (1),

$$
\left.\mathrm{CO}_{2} \text { Loading (mol CO} 2 / \mathrm{kg} \text { solution }\right)=\frac{\int_{0}^{t}\left(C_{\text {in }}-C_{\text {out }}(t)\right) d t}{m_{\text {sol }}}
$$


1 where $C_{\text {in }}$ is the $\mathrm{CO}_{2}$ feed gas rate in $\mathrm{mol} / \mathrm{s}, C_{\text {out }}$ is the $\mathrm{CO}_{2}$ effluent rate in $\mathrm{mol} / \mathrm{s}, t$ is time in second,

2 and $m_{s o l}$ is the mass of solution in $\mathrm{kg}$.

3 In addition, the absorption rate can be described by the derivate of $\mathrm{CO}_{2}$ loading with respect to 4 time is given by equation (2),

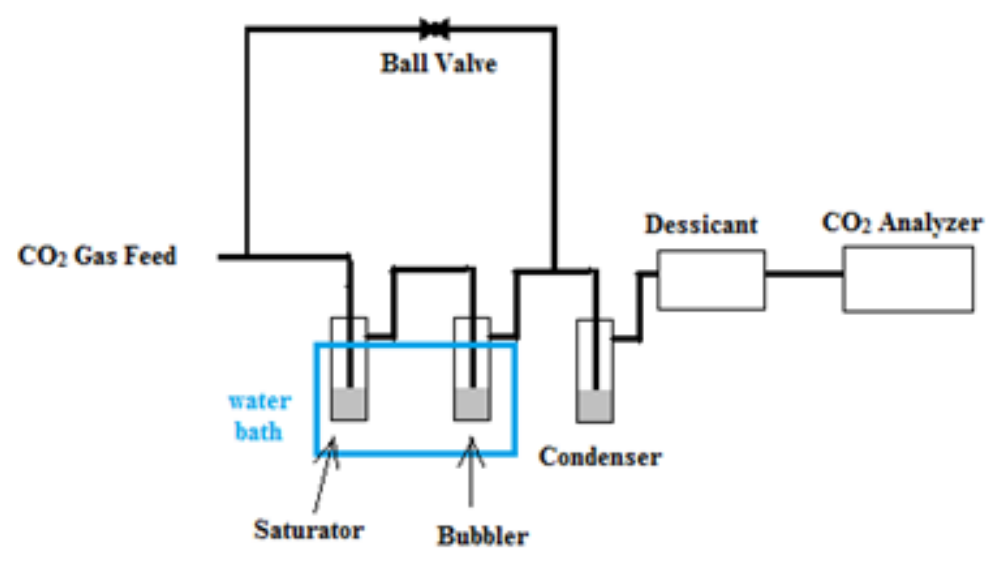

$7 \quad$ Figure 2. Schematic of breakthrough apparatus

\subsection{Determination of Mass Transfer Coefficient by Wetted Wall Column (WWC): Wetted} wall column experiments were conducted as previously reported. ${ }^{31}$ A schematic of the WWC used in this test is shown in Figure 3. In a representative procedure, $30 \mathrm{wt} \%$ aqueous MEA is loaded to a mol $\mathrm{CO}_{2} / \mathrm{mol}$ MEA level of approximately 0.1 with $\mathrm{CO}_{2}$ by sparging the solution reservoir with a concentrated $30 \mathrm{vol} \% \mathrm{CO}_{2} / \mathrm{N}_{2}$ mixture for 6-12 min. Catalyst was added to the solution $(\mathbf{1}, 2.3$

$13 \mathrm{~g} / \mathrm{L})$ to give a clear, yellow solution. The solution is then heated to $40^{\circ} \mathrm{C}$ by circulating through a 14 heat exchanger bath at $180 \mathrm{ml} / \mathrm{min}$. Once the solution is thermally stable, a $\mathrm{CO}_{2}$ gas feed mixed 15 with $\mathrm{N}_{2}$ at $6.6 \mathrm{~L} / \mathrm{min}(3-14.7 \mathrm{vol} \%)$, pre-heated and water saturated by a direct contact heat exchanger, is allowed to contact with the liquid countercurrent on the surface of the column. 
1 Absorption or desorption of $\mathrm{CO}_{2}$ occurs across the contacting area, which gives a $\mathrm{CO}_{2}$

2 concentration difference in the gas stream between the inlet and outlet of the column. Flux and

3 driving force can be obtained from the concentration difference. Four different $\mathrm{CO}_{2}$ concentrations

4 in the gas stream were tested at the same carbon loading. Liquid samples downstream of the WWC

5 were collected during the process for carbon loading, viscosity, density, and $\mathrm{pH}$ measurements.

6 The above procedure was repeated for different carbon loadings.

7 The overall mass transfer coefficient at the operating condition can be calculated from equation $8 \quad(3)$,

$$
K_{G}=\frac{N_{\mathrm{CO}_{2}}}{A \Delta P_{\mathrm{CO}_{2}}}
$$

9 in which $N_{C O 2}$ is the flux of $\mathrm{CO}_{2}, K_{G}$ is the overall mass transfer coefficient, $\triangle P_{\mathrm{CO}}$ is the log mean 10 of $\mathrm{CO}_{2}$ partial pressure, and $A$ is the contacting surface area. Diffusivity of $\mathrm{CO}_{2}$, which is not 11 directly measured in this work, can be calculated from a modified Stokes-Einstein equation in 12 equation (4),

$$
\left(D_{\mathrm{CO}_{2}}\right)_{\text {amine soln }}=\left(D_{\mathrm{CO}_{2}}\right)_{\text {water }}\left(\frac{\eta_{\text {water }}}{\eta_{\text {amine soln }}}\right)^{0.8}
$$

13 in which $D_{\mathrm{CO} 2}$ is the diffusivity of $\mathrm{CO}_{2}$ in amine solution or water, and $\eta$ is the viscosity of amine 14 solution or water.

15 The flux is calculated by the $\mathrm{CO}_{2}$ concentration difference at the inlet and outlet of the wetted wall 16 column as shown equation 5 , 


$$
N_{\mathrm{CO}_{2}}=N_{\mathrm{CO}_{2}}^{i n}-N_{\mathrm{CO}_{2}}^{\text {out }}=y_{\mathrm{CO}_{2}}^{i n} N_{t}^{i n}-y_{N_{2}}^{i n} N_{t}^{i n} \frac{y_{\mathrm{CO}_{2}}^{\text {out }}}{y_{N_{2}}^{\text {out }}}
$$

1 in which the molar flow rates $N_{t}$ were calculated from total volume flue rate at standard condition,

$2 y_{i}$ is the molar fraction of component $i$.

3 Since the $\mathrm{CO}_{2}$ dynamically transfers from gas phase to liquid phase, the partial pressure of $\mathrm{CO}_{2}$

4 decreases along the wetted wall column. To better represent the true average partial pressure of

$5 \mathrm{CO}_{2}$ in the column, log mean of the driving forces was taken at the inlet and the outlet of the

6 column, as given by equation (6),

$$
\Delta P_{\mathrm{CO}_{2}}=\frac{P_{\mathrm{CO}_{2}}^{\text {in }}-P_{\mathrm{CO}_{2}}^{\text {out }}}{\ln \left(\frac{P_{\mathrm{CO}_{2}}^{\text {in }}-P_{\mathrm{CO}_{2}}{ }^{*}}{P_{\mathrm{CO}_{2}}^{\text {out }}-P_{\mathrm{CO}_{2}}{ }^{*}}\right)}
$$

7 in which $P_{\mathrm{CO}_{2}}{ }^{i}$ is the partial pressure of $\mathrm{CO}_{2}$, as shown in equation (7).

$$
P_{\mathrm{CO}_{2}}^{i}=y_{\mathrm{CO}_{2}}^{i}\left(P_{\text {tot al }}-P_{\text {wat er }}\right)
$$

8 As the feed gas is saturated with water in the saturator, the partial pressure of water can be written 9 as its saturation pressure at the temperature $\mathrm{T}$ from equation (8).

$$
P_{\text {wat er }}^{i}=\exp \left(7255-\frac{7207}{T}-7.139 \mathrm{n}(T)+4.04 \times 10^{6} \mathrm{~T}^{2}\right)
$$

10 The equilibrium partial pressure of $\mathrm{CO}_{2}, P^{*}{ }_{\mathrm{CO}}$, can be calculated by making the flux $\mathrm{N}_{\mathrm{CO} 2}$ to be 11 zero at zero driving force through an iterative routine in MATLAB where the two equations are 
1 simultaneously solved. A typical relationship of flux $\mathrm{N}_{\mathrm{CO} 2}$ and driving force of $\mathrm{CO}_{2}$ is shown in

2 Figure 4. The linearity of the two indicates a pseudo first order approximation.

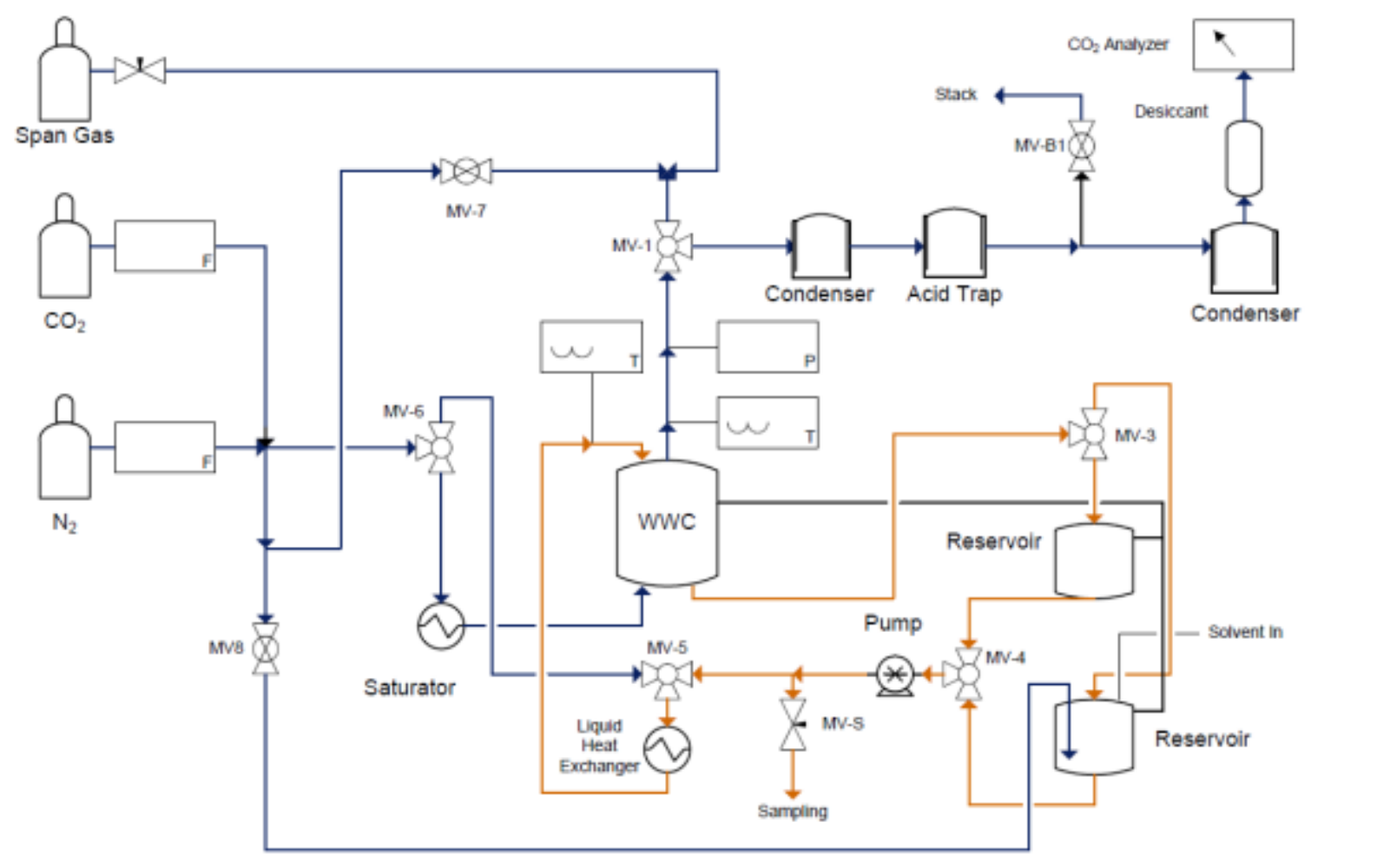

4 Figure 3. Schematic of wetted wall column apparatus utilized for mass transfer coefficient 5 measurements.

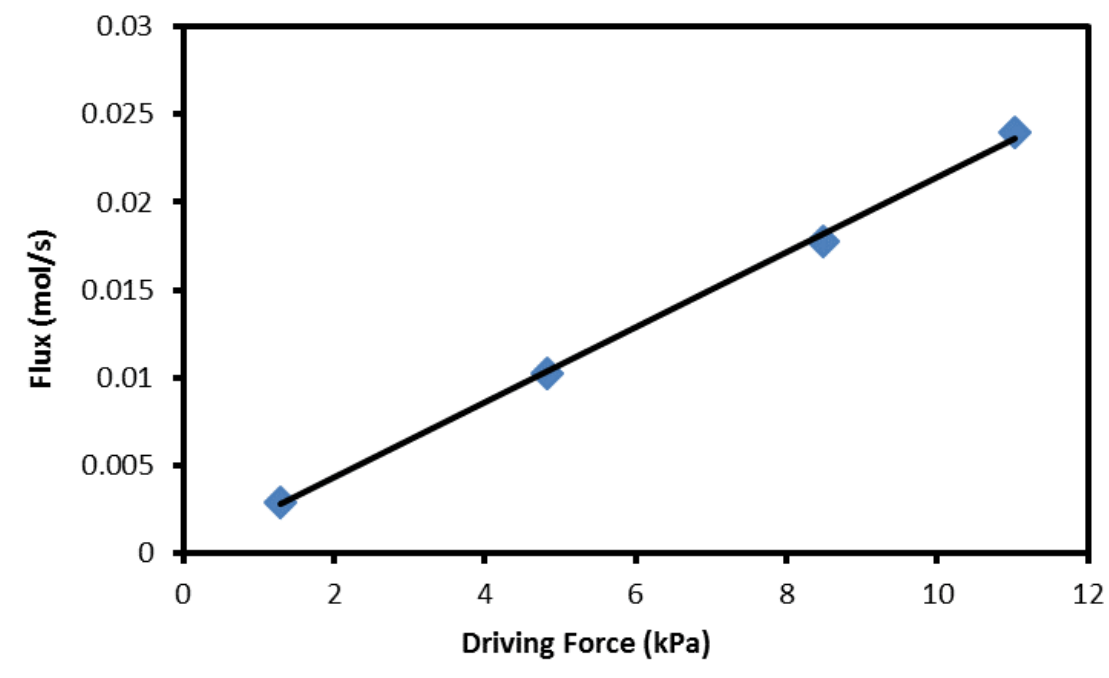


1 Figure 4. A typical relationship of flux $N_{C O 2}$ and driving force of $\mathrm{CO}_{2}$ from wetted wall column

2 experiment.

2.5. Effects of Flue Gas Contaminants on Catalyst Activity. In a representative procedure, a stock solution of 1 at a loading of $2.3 \mathrm{~g} / \mathrm{L}$ was prepared in $5 \mathrm{M}$ aqueous MEA (250 mL). A $25 \mathrm{~mL}$ aliquot of the stock solution was treated with $1000 \mathrm{ppm} \mathrm{NaNO}_{2}\left(0.250 \mathrm{~g}\right.$ of $\left.\mathrm{NaNO}_{2}\right)$ for 24 hours followed by evaluation in the $\mathrm{pH}$-drop apparatus for the above method. This method was repeated concentration of $3000 \mathrm{ppm} \mathrm{NO}$ and $\mathrm{SO}_{\mathrm{x}}$ derived salts. Gaseous $\mathrm{NO}_{\mathrm{x}}$ contaminants were generated in-situ and bubbled through a $25 \mathrm{~mL}$ aliquot of the stock solution containing $\mathbf{1}$ for 30 min prior to evaluation via the $\mathrm{pH}$-drop apparatus. For the generation of $\mathrm{NO}_{\mathrm{x}}$ gas, a $100 \mathrm{~mL}$ two-necked round bottom flask was charged with solid $\mathrm{NaNO}_{2}(2.25 \mathrm{~g}, 33 \mathrm{mmol})$ and a magnetic stir bar. One neck was sealed with a rubber septum, and the other was fitted with a glass adapter containing a hose barb. Rubber tubing was attached via the hose barb adapter and a needle was fitted to the end of the rubber tubing. Concentrated sulfuric acid was added drop wise through the septum with constant stirring resulting in the immediate appearance of a brown fume.

2.6. Thermal Stability. In a representative procedure, a stock solution of $\mathbf{1}(2.3 \mathrm{~g} / \mathrm{L})$ was prepared

17 in $5 \mathrm{M}$ aqueous MEA solution. A $50 \mathrm{~mL}$ aliquot was taken from the stock solution and $14 \% \mathrm{CO}_{2}$ gas with $\mathrm{N}_{2}$ span was bubbled through the solution until a $\mathrm{pH}$ of 10.5 was reached. The solution was transferred to an autoclave, sealed, placed in an oven, and heated at $145{ }^{\circ} \mathrm{C}$ for 92 hours. The autoclave was then removed from the oven and cooled to room temperature. The activity of the

21 catalyst was assayed by taking a $25 \mathrm{~mL}$ aliquot and evaluating via the $\mathrm{pH}$-drop method as described 22 above. 
2 Figure 5. Simplified process flow diagram of integrated bench scale $\mathrm{CO}_{2}$ capture system.

3 Figure 5 shows the schematic of the integrated bench-scale absorption/regeneration system which

4 consists of a $7.6 \mathrm{~cm}$ ID clear PVC scrubber with a $2 \mathrm{~m}$ height of packing, a $7.6 \mathrm{~cm}$ ID stainless

5 steel stripper with a $2 \mathrm{~m}$ height of packing, and a condenser for solvent recovery in the stripper

6 exhaust. The packing inside both absorber and stripper are $6 x 6 \mathrm{~mm}$ ceramic Raschig rings. A

7 decoupled heater and a chiller are installed to provide sensible heat for rich solvent heating and

8 lean solvent cooling to enhance the flexibility of the experimental matrix. A hot oil system is

9 installed to provide necessary heat for solvent regeneration. Liquid flow rate is controlled by 2 centrifugal pumps. Two in-line flow meters have been installed to monitor the volumetric solvent

11 flow rates both entering and exiting the stripper. Feed gas is supplied by two mass flow controllers

12 (MFC) deployed to control the $\mathrm{CO}_{2}$ and $\mathrm{N}_{2}$ flow rates. $\mathrm{CO}_{2}$ and $\mathrm{N}_{2}$ are mixed to simulate flue gas

13 conditions of $14 \% \mathrm{CO}_{2}$ at a total flow rate of $30 \mathrm{~L} / \mathrm{min}$. The gases are sent through a water saturator 
1 and then injected to the bottom of the absorber. A Horiba $\mathrm{CO}_{2}$ analyzer is used to measure the

2 online $\mathrm{CO}_{2}$ concentration at the absorber outlet.

3 The measurements of $\mathrm{CO}_{2}$ absorption efficiency and rich solution regeneration energy requirement

4 at various conditions were performed during the bench-scale parametric study. The $\mathrm{CO}_{2}$ absorption

5 efficiency is related to the gas inlet and outlet $\mathrm{CO}_{2}$ flow rates by equation (9):

$$
\varphi_{\mathrm{CO}_{2}}=\frac{n_{\mathrm{CO}_{2}}^{\text {in }}-n_{\mathrm{CO}_{2}}^{\text {out }}}{n_{\mathrm{CO}_{2}}^{\text {in }}}
$$

6 where $\varphi_{\mathrm{CO}_{2}}, \mathrm{CO}_{2}$ capture efficiency, $\% ; n_{\mathrm{CO}_{2}}^{\text {in }}$, gas inlet $\mathrm{CO}_{2}$ mole flow rate, $\mathrm{mol} / \mathrm{s} ; n_{\mathrm{CO}_{2}}^{\text {out }}$, gas outlet

$7 \mathrm{CO}_{2}$ mole flow rate, mol/s. The inlet $\mathrm{CO}_{2}$ flow rate, $n_{\mathrm{CO}_{2}}^{\text {in }}$ was calculated directly from the $\mathrm{CO}_{2}$

8 MFC flow rate. The outlet $\mathrm{CO}_{2}$ flow rate was calculated by equation (10):

$$
n_{C O_{2}}^{\text {out }}=C_{C O_{2}}^{\text {out }} \frac{V_{N_{2}}^{\text {in }}}{1-C_{C O_{2}}^{\text {out }}}
$$

9 where $C_{\mathrm{CO}_{2}}^{\text {out }}$, outlet $\mathrm{CO}_{2}$ concentration, $\% ; V_{N_{2}}^{\text {in }}$, inlet $\mathrm{N}_{2}$ flow rate, $\mathrm{L} / \mathrm{min}$. the outlet $\mathrm{CO}_{2}$ 10 concentration, $\mathrm{C}_{\mathrm{CO}_{2}}^{\text {out }}$ was measured by an Horiba $\mathrm{CO}_{2}$ analyzer, which was calibrated 11 before each test. The inlet $\mathrm{N}_{2}$ flow rate, $V_{N_{2}}^{\text {in }}$ was obtained from the MFC.

12 The rich $\mathrm{CO}_{2}$ solution regeneration energy is calculated from the reboiler heat duty assuming an 13 adiabatic system by equation (11):

$$
Q_{C O_{2}}^{o v}=\frac{Q_{R}}{n_{C O_{2}}^{\text {in }}-n_{C O_{2}}^{o u t}}
$$

14 where $Q_{\mathrm{CO}_{2}}^{\mathrm{ov}}$, overall regeneration energy per unit of $\mathrm{CO}_{2}$ regeneration, $\mathrm{kJ} / \mathrm{mol} \mathrm{CO}_{2} ; Q_{R}$, reboiler 15 heat duty, $\mathrm{kW}$. The reboiler heat was provided by hot oil recirculation, the heat duty $Q_{R}$ is 16 calculated by equation (12):

$$
Q_{R}=C_{p}^{o i l} m_{o i l} \rho_{o i l}\left(T_{R}^{i n}-T_{R}^{o u t}\right)
$$


1 where $C_{p}^{\text {oil }}$, hot oil heat capacity, $\mathrm{kJ} / \mathrm{g} / \mathrm{K} ; m_{\text {oil }}$, hot oil flow rate, $\mathrm{L} / \mathrm{s} ; \rho_{\text {oil }}$, hot oil density, $\mathrm{g} / \mathrm{L} ; T_{R}^{i n}$,

2 reboiler inlet temperature, ${ }^{\circ} \mathrm{C} ; T_{R}^{\text {out }}$, reboiler outlet temperature, ${ }^{\circ} \mathrm{C}$. Mobiltherm 603 heat transfer

3 oil was used in the reboiler system.

4

\section{Results}

3.1. Solvent Properties. The development of homogenous $\mathrm{CO}_{2}$ hydration catalysts for industrial CCS processes is a complex task, with multiple competing determinate factors. Monoethanolamine (MEA) is the most widely investigated solvent due to its low cost and fast kinetics for $\mathrm{CO}_{2}$ absorption. However, there are concerns over the commercial implementation due to the high energy cost for solvent regeneration and thermal degradation rates associated with MEA solvents. ${ }^{3,}$ ${ }^{33}$ To circumvent these disadvantages we formulated a blended solvent consisting of a thermally stable primary amine and a sterically-hindered primary amine, 1-amino-2-propanol (A2P) and 2amino-2-methyl-1-propanol (AMP). ${ }^{34}$ Sterically-hindered amines such as AMP tend to exhibit slower kinetics of $\mathrm{CO}_{2}$ absorption, ${ }^{35}$ making them ideally suited for enhancement by the addition of a catalytic additive to increase capture rate. If the absorption rate of a hindered amine solvent can be brought close to that of a fast solvent such as MEA, the combination of a faster reaction rate, lower degradation rate, and lower regeneration energy would give a preferable solvent mixture with fast absorption, low energy requirements, and low solvent makeup.

The reactions of aqueous alkanolamines with $\mathrm{CO}_{2}$ have been studied by a variety of methods, and are widely discussed in the literature. ${ }^{19,35-42}$ The rate of MEA-carbamate formation with $\mathrm{CO}_{2}\left(k_{2}\right)$ is widely debated in the literature and varies from $4000 \mathrm{M}^{-1} \mathrm{~s}^{-1}$ to $8000 \mathrm{M}^{-1} \mathrm{~s}^{-1}$, with the most common values between $5000-6000 \mathrm{M}^{-1} \mathrm{~s}^{-1}$, depending on the method, conditions, $\mathrm{pH}$, and temperature..$^{36-37,39,43-49}$ Additional studies have discussed the individual kinetics of A2P and AMP 
1 amine solutions. ${ }^{35,39-40,46,50}$ The reported $k_{2}(298 \mathrm{~K})$ values for the reaction of $\mathrm{CO}_{2}$ with $\mathrm{A} 2 \mathrm{P}$ are

$24400-5300 \mathrm{M}^{-1} \mathrm{~s}^{-1},{ }^{35,50}$ while the more sterically-hindered AMP is much slower with reported

3 values of $502-810 \mathrm{M}^{-1} \mathrm{~s}^{-1} .{ }^{40,46}$ The blended A2P/AMP solvent is therefore expected to exhibit

4 slower kinetics than the MEA base case, however the addition of a catalyst to boost absorption

5 kinetics in combination with lower regeneration energy and decreased solvent makeup from

6 degradation (vide infra) would make the A2P/AMP solvent blend a competitive alternative to

7 MEA.

8 In order to have a robust solvent for commercialization, long-term thermal stability of the amines

9 is critical, as the capture solvents are often exposed to high temperatures during the $\mathrm{CO}_{2}$ capture

10 process which is solvent- and stripper operating pressure-dependent. MEA has well-documented

11 thermal degradation at temperatures above $120{ }^{\circ} \mathrm{C} .{ }^{51-53}$ The thermal stability of the novel

12 A2P/AMP solvent blend was examined, relative to MEA, through extended and constant exposure

13 to elevated temperatures of $125^{\circ} \mathrm{C}, 135^{\circ} \mathrm{C}$, and $145^{\circ} \mathrm{C}$ for 168 hours. The A2P/AMP blend shows

14 a 70\% decrease in the rate of amine loss (as percent of initial) at the high temperatures associated

15 with stripper conditions over a 168 hour period (Figure 6).

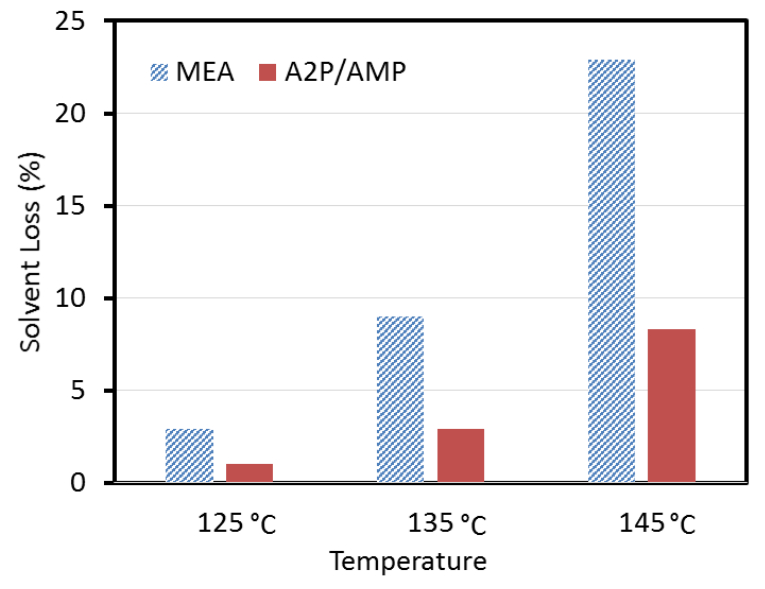


1 Figure 6. Thermal degradation (\% loss) of carbon loaded MEA and A2P/AMP at stripping

2 temperatures over $168 \mathrm{~h}, \alpha=0.45 \mathrm{~mol} \mathrm{C} / \mathrm{mol} \mathrm{N}$, for both MEA and A2P/AMP.

3 Physical solvent properties such as viscosity ${ }^{54}$ and surface tension ${ }^{55}$ are known to impact the

4 solution side diffusion and mass transfer resistance for reactants and products, and an increase in

5 these properties have been associated with decreasing mass flux of $\mathrm{CO}_{2}$ into capture solutions.

6 Surface elasticity is an indication of surfactant-like behavior and is a key factor in solvent

7 foaming, ${ }^{56}$ which can lead to detrimental process implications for industrial systems. ${ }^{57}$ For these

8 reasons it was imperative to determine the effect of $\mathbf{1}$ on the solvent physical properties, if notable.

9 The viscosity, surface tension, and elasticity of the carbon capture solutions were measured at

10 carbon loadings across the solvent operational range $(\alpha=0-0.55)$ in the absence and presence of

11 1. Solutions of MEA and A2P/AMP solvent containing $2.3 \mathrm{~g} / \mathrm{L}$ of 1 were compared to baseline

12 solutions of the solvent with no additional additive. As can be seen in Figure 7a and $7 \mathbf{b}$, there are

13 no observable differences in viscosity for both solvents, and a small decrease in surface tension in

14 MEA at high loadings $(\alpha>0.3)$ by the addition of 1 . The surface elasticity of A2P/AMP solutions

15 is unaffected by the addition $\mathbf{1}$, indicating $\mathbf{1}$ is not acting as a surfactant in A2P/AMP, however

16 there is a sharp increase in elasticity upon the addition of $\mathbf{1}$ to MEA (Figure 7c). This increase in

17 surface elasticity is accompanied by the presence of solvent foaming when simulated flue gas is

18 bubbled into solutions of MEA $+\mathbf{1}$ (Figure 7d), which is also observed in $\mathrm{pH}$ drop and

19 breakthrough experiments, and precluded the use of this solvent mixture in packed column

20 experiments (vide infra). 


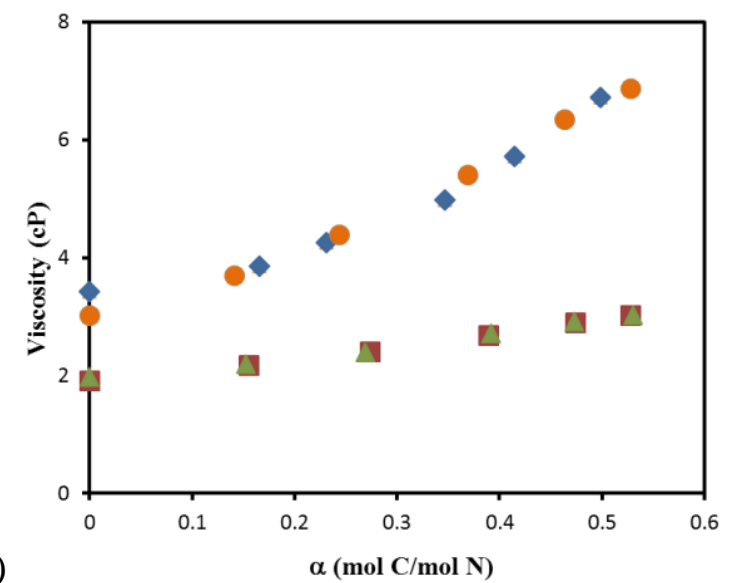

1

(a)

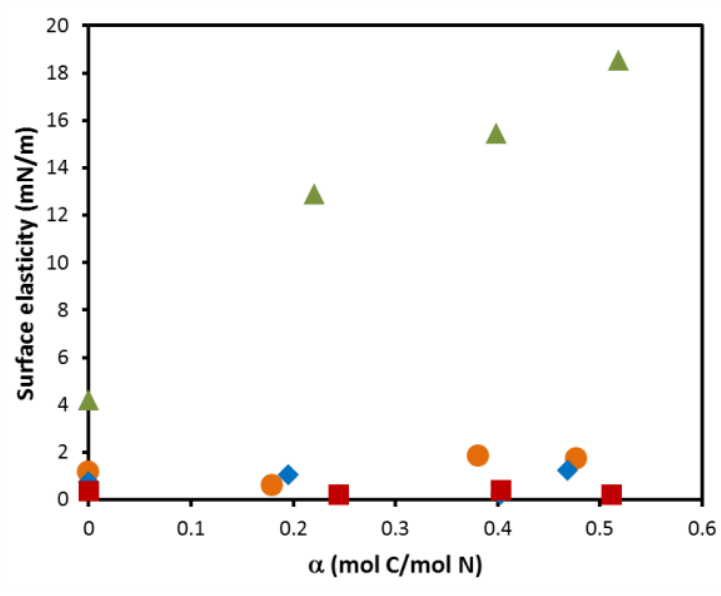

2 (c)

(d)

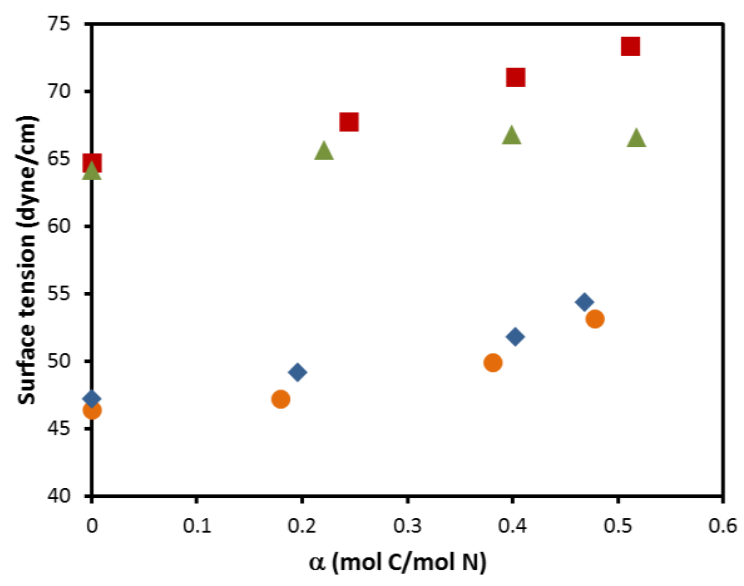

(b)

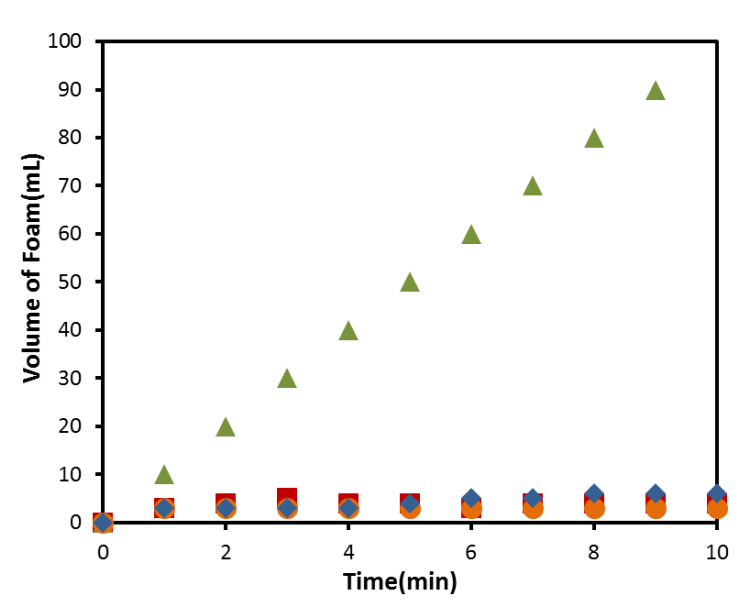

3 Figure 7. (a) Viscosity (b) surface tension and (c) surface elasticity versus carbon loading for 4 carbon capture solutions with and without additive 1. (d) Foaming versus time for carbon capture 5 solutions with and without additive 1. $(\boldsymbol{\square}=30 \mathrm{wt} . \% \mathrm{MEA}, \boldsymbol{\Delta}=\mathrm{MEA}+2.3 \mathrm{~g} / \mathrm{L} \mathrm{1}, \bullet=\mathrm{A} 2 \mathrm{P} / \mathrm{AMP}$, 6 = A2P/AMP + $2.3 \mathrm{~g} / \mathrm{L} \mathrm{1})$.

7 3.2. Initial Screening. For evaluation of the influence of 1 on reaction kinetics, a pH drop method was used as a quick screening process. ${ }^{27}$ The activity of $\mathbf{1}$ and its propensity to improve overall mass transfer was evaluated by bubbling simulated flue gas $\left(14 \% \mathrm{CO}_{2} / \mathrm{N}_{2}\right.$ balanced) into solutions of $5 \mathrm{M}$ MEA and A2P/AMP containing 1, and compared to the reference amine solutions. As the

11 acid gas $\left(\mathrm{CO}_{2}\right)$ is absorbed into an amine solvent, there is a decrease in the $\mathrm{pH}$ of the solution as 12 protons are released to balance carbamate/bicarbonate formation. Therefore, in $\mathrm{pH}$ drop 13 experiments a more negative slope is a qualitative indication of a more rapid absorption of $\mathrm{CO}_{2}$ by 
1 the solvent under the same setup and operating conditions. As shown in Figure 8, a significant

2 enhancement in $\mathrm{CO}_{2}$ absorption is observed upon the addition of $\mathbf{1}$ to both solvents, as indicated

3 by the increased slope of the $\mathrm{pH}$ drop curve (Figure 8a) (e.g. increased rate of $\mathrm{CO}_{2}$ absorption,

4 Figure 8b), relative to additive-free baseline for both $5 \mathrm{M}$ MEA and the A2P/AMP blended

5 solvent. The large difference between the MEA and A2P/AMP baseline rates is expected, as MEA

6 is well known to be a kinetically fast solvent, while A2P/AMP is formulated to be kinetically

7 slower with lower solvent regeneration energy and higher thermal stability. These preliminary $\mathrm{pH}$

8 drop experiments indicate that addition of 1 results in an increased $\mathrm{CO}_{2}$ absorption rate in both

9 solvents, however the observation of foaming in solutions of MEA $+\mathbf{1}$ at higher loadings is

10 concerning from a process standpoint, and the surfactant-like activity of $\mathbf{1}$ in MEA makes it

11 difficult to determine if the observed enhancement in MEA is from catalytic activity, surfactant-

12 like behavior, or a combination of both.

13

(a)

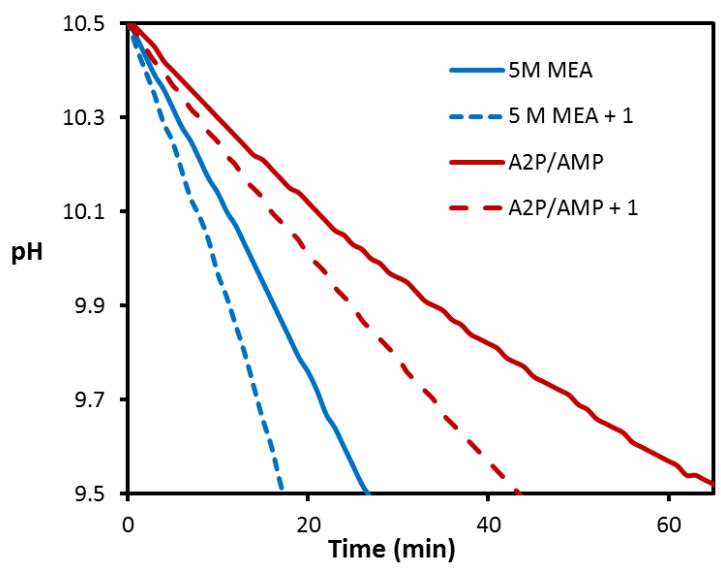

(b)

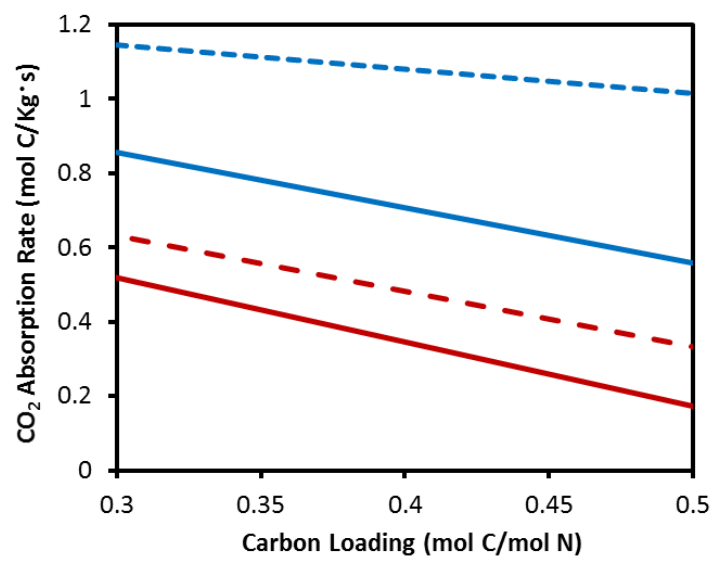

14 Figure 8. (a) $\mathrm{pH}$ drop kinetics testing of 5M MEA (-), 5M MEA with additive 1 (--), A2P/AMP

15 (-), and A2P/AMP with additive 1 (--), and (b) corresponding $\mathrm{CO}_{2}$ removal rate.

3.3. Determination of $\mathrm{CO}_{2}$ Removal Rate. After the success of the initial activity screening by $\mathrm{pH}$ drop, we sought to obtain a more quantitative determination of the enhancement in $\mathrm{CO}_{2}$ 
removal kinetics enhancement facilitated via the addition of 1 into MEA and A2P/AMP capture

2 solutions. In the breakthrough experiment there is extensive mixing between the gas bubbles and

3 the liquid, and therefore diffusion resistance in the gaseous layer and bulk liquid is lowered to

4 allow for observation of the kinetics from the reaction resistance. The breakthrough data in Figure

5 9a shows an increase in $\mathrm{CO}_{2}$ removal rate (relative to the solvent baseline), over the entire

6 absorption range, upon the addition of 1 to both $5 \mathrm{M} \mathrm{MEA}$ and A2P/AMP solvents. However,

7 foaming of the MEA +1 solution is again observed at higher loadings $(\alpha>0.3)$.
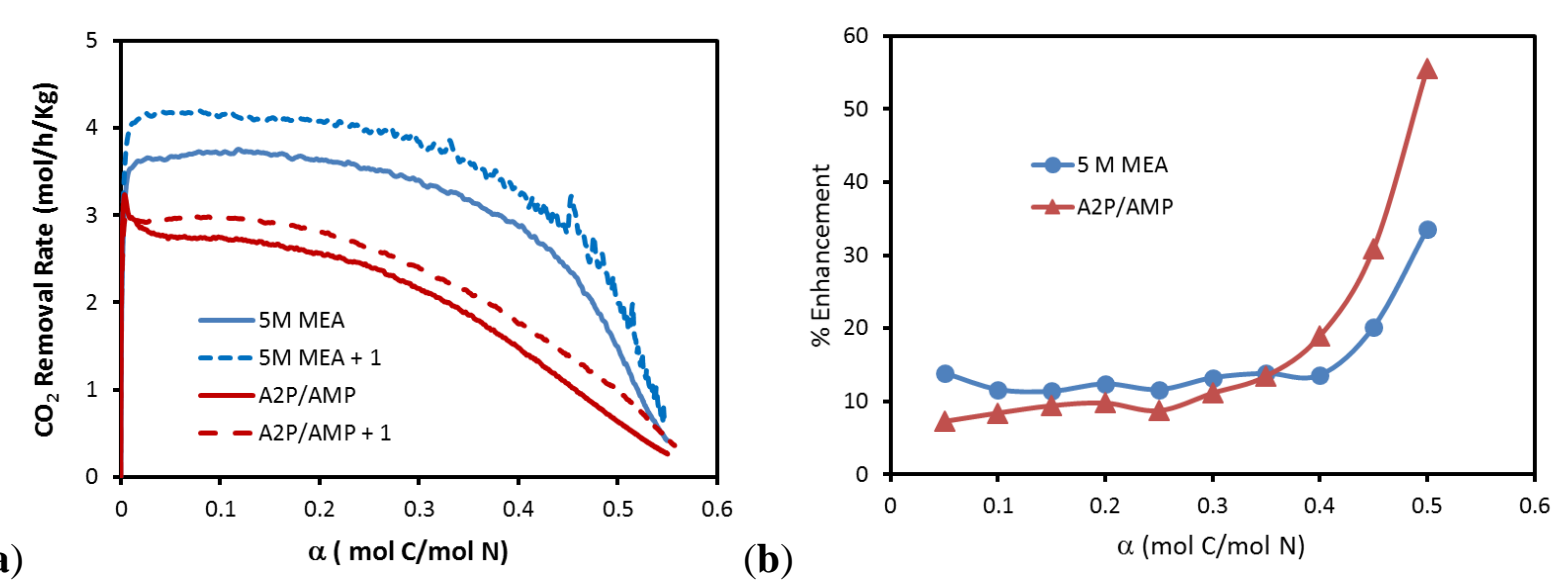

$8 \quad(\mathbf{a})$

(b)

9 Figure 9. (a) Breakthrough data for carbon capture solvents with and without additive 1 in MEA 10 and A2P/AMP (14\% $\mathrm{CO}_{2}$ inlet). (b) Percent enhancement in $\mathrm{CO}_{2}$ removal rate upon addition of 1 to MEA (blue) and A2P/AMP (red) capture solvents.

In a typical absorber column, absorption kinetics are faster at the top of the column where the capture solution is lean $(\alpha<0.30)$, and the rate decreases as more $\mathrm{CO}_{2}$ is absorbed and the concentration of free amine decreases. The slowest absorption rates are observed with rich solutions $(\alpha>0.40)$ at the bottom of the column, requiring additional residence time or absorber

17 height, for diminishing returns at higher loadings. The MEA samples show a higher removal rate than A2P/AMP as expected, but both solvents show enhancement upon addition of 1. A greater degree of enhancement would translate to less additional absorber height required to obtain a 
1 similar increase in rich loading, and save on capital cost in absorber construction. As observed in

2 controlled laboratory-scale testing, additive 1 enhanced mass transfer at higher carbon loadings ( $\alpha$

$3>0.40)$ where decreasing concentration of free amine limits the overall mass transfer rate, and

4 increasing viscosity of the capture solvent increases liquid resistance to mass transfer. The results

5 shown in Figure 9b demonstrate that the catalyst provides mass transfer enhancement over the

6 entire range, however the degree of enhancement is not uniform. The percent enhancement at lower

7 loadings is between $7-13 \%$ upon addition of $\mathbf{1}$, but at higher loadings $(\alpha>0.4$ for MEA and $\alpha>$

80.25 for A2P/AMP) the enhancement increases significantly. Interestingly, the two curves cross at

$9 \alpha=0.35$ and a much larger maximum enhancement is observed for the slower A2P/AMP solvent

10 (55 \% at $\alpha=0.5)$, while the faster MEA solvent shows a 33\% enhancement at $\alpha=0.5$. The

11 increased enhancement at higher loadings is a good indication that $\mathbf{1}$ is preforming as designed,

12 catalyzing the $\mathrm{CO}_{2}$ hydration reaction that becomes more prevalent at higher loadings where the

13 concentration of free amine is diminished.

14 To include the liquid side diffusion resistance in the experiment, the mass transfer coefficient of $15 \mathrm{CO}_{2}$ transfer was measured in $5 \mathrm{M}$ MEA and A2P/AMP solvents, with and without 1 , at $40{ }^{\circ} \mathrm{C}$ on 16 a wetted wall column (WWC) to approximate conditions in the absorber. The data in Figure 10a 17 shows the effect of carbon loading on the mass transfer coefficient, as an average of three (3) 18 replicate runs. As with the breakthrough data, addition of 1 to the $5 \mathrm{M}$ MEA capture solvent 19 showed improvement in mass transfer over the entire experimental range, but at a relatively low 20 magnitude. 


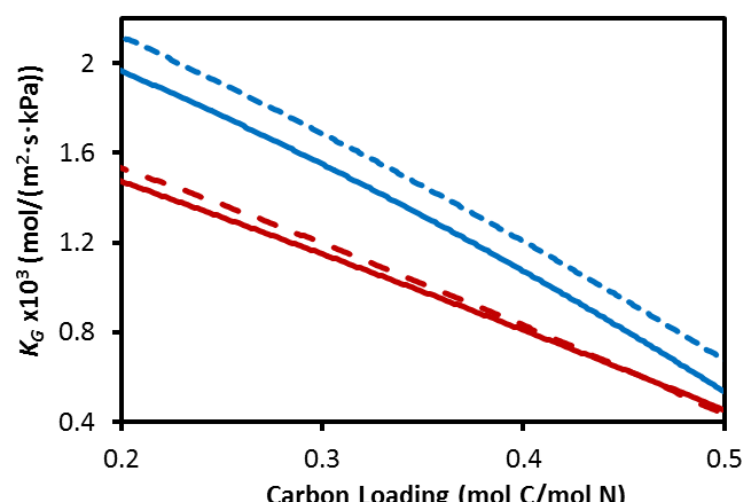

(a)

Carbon Loading ( $\mathrm{mol} \mathrm{C} / \mathrm{mol} \mathrm{N})$

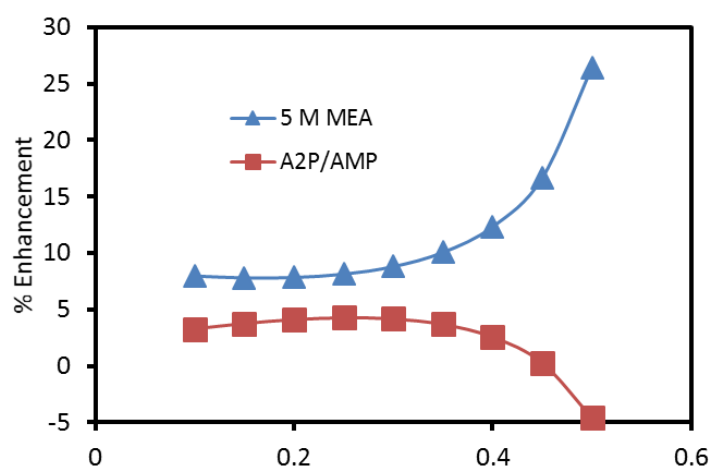

(b)

Carbon Loading ( $\mathrm{mol} \mathrm{C} / \mathrm{mol} \mathrm{N})$

2 Figure 10. (a) Overall mass transfer coefficient $\left(\mathrm{K}_{\mathrm{G}}\right)$ versus $\mathrm{CO}_{2}$ loading from wetted wall

3 column. $5 \mathrm{M}$ MEA baseline (solid blue), $5 \mathrm{M} \mathrm{MEA} \mathrm{+} \mathrm{2.3} \mathrm{g/L} 1$ (blue dashed); A2P/AMP

4 baseline (red solid), A2P/AMP + $2.3 \mathrm{~g} / \mathrm{L} 1$ (red dashed). (b) Percent enhancement versus carbon

5 loading for MEA and A2P/AMP solutions containing 1 over respective baseline.

6 The effect of $\mathbf{1}$ on mass transfer was also examined for solutions of A2P/AMP (Figure 10a),

7 although no significant enhancement was observed. The mass transfer of both the baseline and

8 solutions containing 1 are equal near $\alpha=0.5$ (Figure 10b). This lack of activity in A2P/AMP is

9 inconsistent with the breakthrough data described in Figure 9, but represents one of the difficulties

encountered in transitioning from highly controlled fundamental laboratory tests to more process

11 relevant testing approaches. While the breakthrough experiment lowers diffusion resistance in

12 order to isolate and analyze changes in the reaction resistance, the wetted-wall experiment

13 maximizes diffusion resistance to allow for the identification of the mass transfer coefficients $\left(K_{g}\right)$.

14 By maximizing diffusion resistance in a kinetically slow, more viscous solvent such as the A2P/AMP blend, it is not surprising that no enhancement is observed in the WWC from a catalyst such as $\mathbf{1}$ that is designed to reduce only the reaction resistance. However, neither of these

17 experiments are actually representative of conditions in a packed absorber column and it is 18 important to conduct packed-column testing to determine enhancement when reaction and diffusion resistance are combined under process-relevant conditions (vide infra). 
1 In order to examine the stability of 1 toward degradation by $\mathrm{NO}_{\mathrm{x}}$ and $\mathrm{SO}_{\mathrm{x}}, \mathrm{pH}$ drop experiments

2 were conducted in both capture solvents in the presence of $1000 \mathrm{ppm} \mathrm{NO}_{\mathrm{x}}$, and $\mathrm{SO}_{\mathrm{x}}$ derived

3 products. These concentrations are considered to be in the operational range of an amine-based

4 capture process, ${ }^{58}$ and no decrease in activity was observed (Figure 11a). Experiments were also

5 conducted where solutions containing 1 were exposed to a large excess $\mathrm{NO}_{\mathrm{x}}$ gas, generated from

$6 \mathrm{NaNO}_{2}$ and $\mathrm{H}_{2} \mathrm{SO}_{4}$ (see experimental section 2.5), as well as with all contaminants combined

7 together. As shown in Figure 11b, negligible changes were observed in the $\mathrm{pH}$ drop testing,

8 suggesting that $\mathrm{NO}_{\mathrm{x}}$ and $\mathrm{SO}_{\mathrm{x}}$ derived components do not affect the ability of $\mathbf{1}$ to increase mass

9 transfer of the capture solutions.

10

(a)

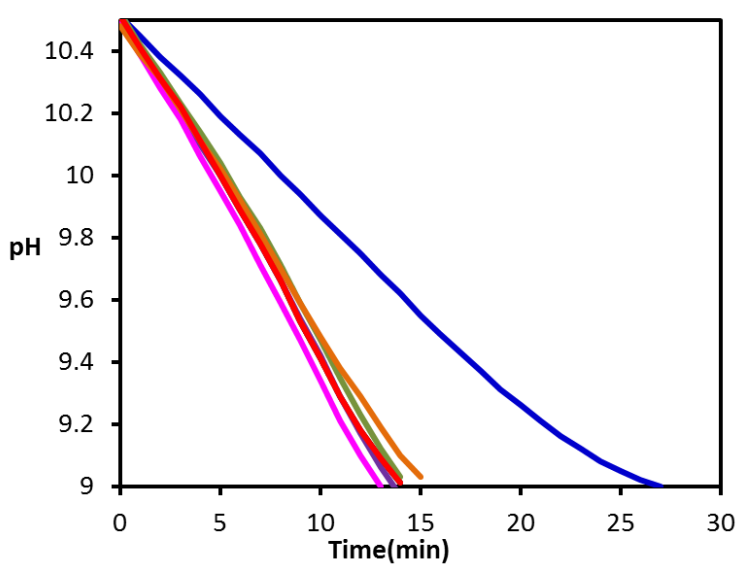

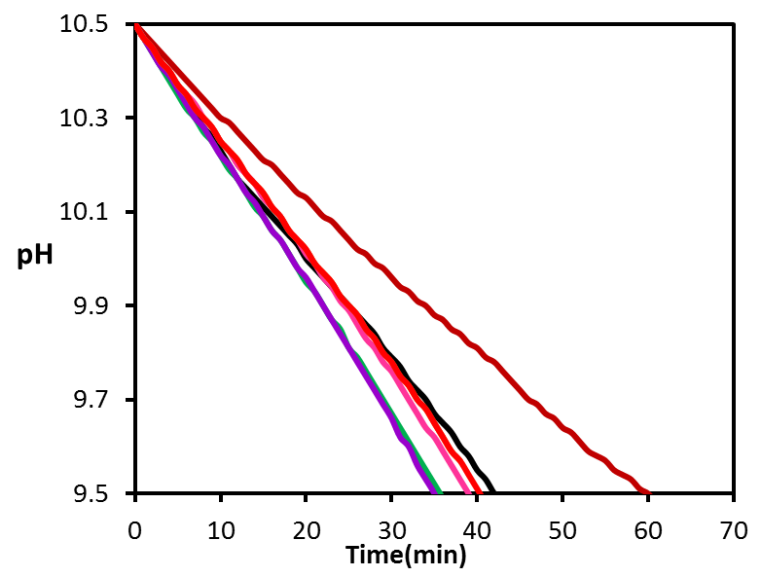

Figure 11. $\mathrm{pH}$ drop testing of the stability of 1 toward $\mathrm{NO}_{\mathrm{x}}$ and $\mathrm{SO}_{\mathrm{x}}$ oxidative contaminants in MEA and A2P/AMP capture solutions. $(\mathbf{a})$ blue $=5 \mathrm{M}$ MEA baseline; black $=\mathrm{MEA}+\mathbf{1}$, green $=$ $\mathrm{MEA}+\mathbf{1}+1000$ ppm $\mathrm{NaNO}_{3}$, purple $=\mathrm{MEA}+\mathbf{1}+1000$ ppm $\mathrm{NaNO}_{2}$, pink $=\mathrm{MEA}+\mathbf{1}+1000$ ppm $\mathrm{Na}_{2} \mathrm{SO}_{4}$, orange $=\mathrm{MEA}+\mathbf{1}+$ excess $\mathrm{NO}_{\mathrm{x}}$, red $=\mathrm{MEA}+\mathbf{1}+$ all $\mathrm{NO}_{\mathrm{x}} / \mathrm{SO}_{\mathrm{x}} .(\mathbf{b})$ maroon $=$ $\mathrm{A} 2 \mathrm{P} / \mathrm{AMP}$ baseline, black $=\mathrm{A} 2 \mathrm{P} / \mathrm{AMP}+\mathbf{1}$, green $=\mathrm{A} 2 \mathrm{P} / \mathrm{AMP}+\mathbf{1}+1000 \mathrm{ppm} \mathrm{NaNO}_{3}$, purple $=$ $\mathrm{A} 2 \mathrm{P} / \mathrm{AMP}+\mathbf{1}+1000 \mathrm{ppm} \mathrm{NaNO}$, pink $=\mathrm{A} 2 \mathrm{P} / \mathrm{AMP}+\mathbf{1}+1000 \mathrm{ppm} \mathrm{Na} \mathrm{SO}_{4}$, orange $=$ $\mathrm{A} 2 \mathrm{P} / \mathrm{AMP}+\mathbf{1}+$ excess $\mathrm{NO}_{\mathrm{x}}$, red $=\mathrm{A} 2 \mathrm{P} / \mathrm{AMP}+\mathbf{1}+$ all $\mathrm{NO}_{\mathrm{x}} / \mathrm{SO}_{\mathrm{x}}$.

Elevated temperatures in the carbon capture process are another source of chemical degradation, and an important barrier to commercial viability. It is imperative that any solvent component be stable at the temperatures observed in the stripping process for solvent regeneration. In order to 
1 verify the thermal stability of $\mathbf{1}$, activity assays via $\mathrm{pH}$ drop were performed after exposing solutions of $5 \mathrm{M}$ MEA with and without 1 to $145^{\circ} \mathrm{C}$ for 72 hours and solutions of A2P/AMP with and without 1 to $145^{\circ} \mathrm{C}$ for 144 hours. As shown in Figure 11, there is no decrease in activity 4 observed upon heating for the solvent baseline, or for solutions containing 1. Assuming $10 \%$ residence time in the stripper, we estimate $\mathbf{1}$ would have a lifetime of over 1500 hours in an 6 industrial CCS process.

7

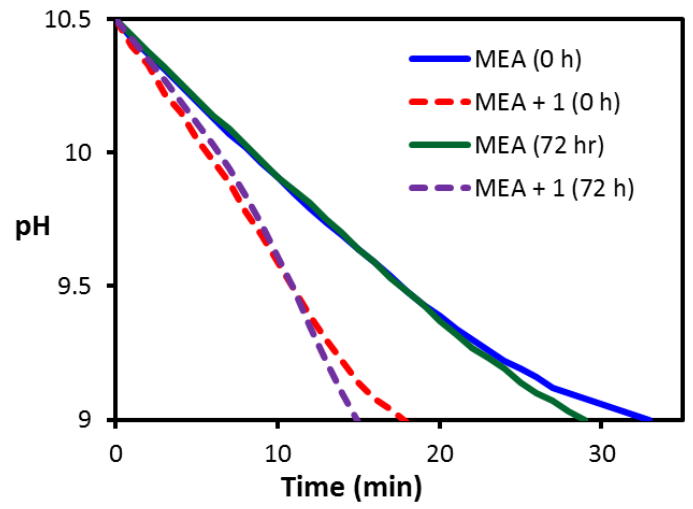

(b)

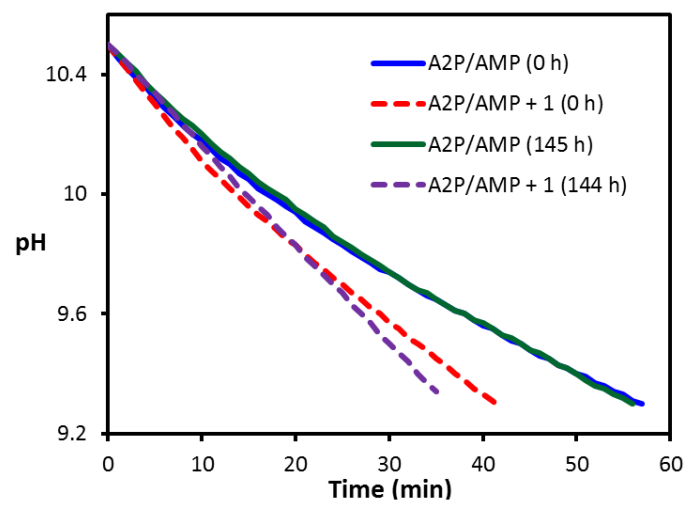

Figure 11. Thermal stability of 1 in solutions of 5 M MEA (a) and the A2P/AMP (b) at $145{ }^{\circ} \mathrm{C}$.

3.5. Integrated Bench-Scale $\mathrm{CO}_{2}$ Capture System. The improved performance and effect on overall energy penalty upon addition of $\mathbf{1}$ was determined using a bench-scale integrated $\mathrm{CO}_{2}$ capture unit. The energy demand and performance of the A2P/AMP +1 solvent blend was compared to both A2P/AMP and 30\% MEA. Solutions of MEA + 1 were not evaluated in the bench-scale apparatus, due to foaming concerns and the possibility of damaging equipment from solvent overflow. To accurately compare the different solvents tested, $\mathrm{CO}_{2}$ capture efficiency was maintained at $90 \%$ and the energy penalty was minimized through adjustment of process parameters (i.e. liquid flow rate (L/G), stripper pressure, and hot oil temperature). The energy penalty for the MEA and A2P/AMP baseline cases were very similar, at 234 and $236 \mathrm{~kJ} / \mathrm{mol} \mathrm{CO}_{2}$, respectively. Although A2P/AMP is designed to improve the overall thermodynamics with the 
1 addition of AMP while maintaining faster kinetics with the addition of A2P, the blended A2P/AMP

2 solvent has similar cyclic capacity as MEA but achieves a much lower rich loading in the absorber

3 column (2.00 vs. $2.51 \mathrm{~mol} \mathrm{CO} / \mathrm{kg})$. Upon the addition of 1 to the A2P/AMP solvent blend, the

4 enhanced absorption kinetics increased the overall capture efficiency, and the liquid flow was

5 decreased in order to maintain the $90 \%$ capture condition. Decreasing the liquid load increases

6 cyclic capacity, as seen in Table 2, reducing the sensible heat requirement and decreasing the

7 overall energy penalty of the A2P/AMP solvent by $21 \%$.

8 Table 2. Reaction conditions and energy demand for $\mathrm{CO}_{2}$ capture in Bench Unit for different 9 solvents.

\begin{tabular}{cccccc} 
Solvent & $\begin{array}{c}\text { Energy } \\
\text { Demand } \\
\left(\mathrm{kJ} / \mathrm{mol} \mathrm{CO}_{2}\right)\end{array}$ & $\begin{array}{c}\text { Capture } \\
\text { Efficiency } \\
(\%)\end{array}$ & $\begin{array}{c}\text { Stripper } \\
\text { Pressure } \\
(\mathrm{kPaa})\end{array}$ & $\begin{array}{c}\text { Cyclic } \\
\text { Capacity } \\
\left(\mathrm{mol} \mathrm{CO}_{2} / \mathrm{kg}\right)\end{array}$ & $\begin{array}{c}\text { Solvent } \\
\text { Flowrate } \\
(\mathrm{mL} / \mathrm{min})\end{array}$ \\
\hline MEA & 234 & 92 & 110 & 0.84 & 150 \\
A2P/AMP & 236 & 92 & 128 & 0.72 & 150 \\
A2P/AMP+1 & 187 & 89 & 179 & 1.37 & 60
\end{tabular}

10

\begin{tabular}{c|ccccc} 
Solvent & $\begin{array}{c}\text { Rich Loading } \\
\left(\mathrm{mol} \mathrm{CO}_{2} / \mathrm{kg}\right)\end{array}$ & $\begin{array}{c}\text { Lean Loading } \\
\left(\mathrm{mol} \mathrm{CO}_{2} / \mathrm{kg}\right)\end{array}$ & $\begin{array}{c}\text { Reboiler } \\
\mathrm{T}\left({ }^{\circ} \mathrm{C}\right)\end{array}$ & $\begin{array}{c}\mathrm{Q}_{\mathrm{R}} \\
(\mathrm{kW})\end{array}$ & $\begin{array}{c}\text { Rich Viscosity } \\
(\mathrm{cP})\end{array}$ \\
\hline MEA & 2.51 & 1.67 & 92 & 0.72 & 3.3 \\
A2P/AMP & 2.00 & 1.28 & 91 & 0.72 & 7.2 \\
A2P/AMP+1 & 2.08 & 0.707 & 106 & 0.52 & 7.4
\end{tabular}

\section{Discussion}

4.1. Catalytic Solvent Evaluation Challenges. Transitioning from the lab-scale testing methods, $\mathrm{pH}$ drop and breakthrough, to the more quantitative engineering testing methods such as the wetted-wall column introduces physical changes in the capture process. The decrease in the overall relative activity of $\mathbf{1}$ within the transition process, i.e. from breakthrough to wetted-wall, raises

17 questions about how these physical differences affect the solvent evaluation between the solvent mixtures since the chemistry in situ remains unchanged. Bubbling simulated flue gas into the capture solution, as in the breakthrough experiment, minimizes the liquid side diffusion resistance 
1 in equation (13), which is maximized in the wetted-wall column. However, the wetted-wall column

2 is heavily influenced by physical properties of the solvent, such as viscosity and surface tension,

3 due to the lack of turbulent force from counter-current gas flow and shearing force from the liquid

4 flow through packing material. These turbulent forces destabilize the liquid film in a packed

5 column and provide more liquid-gas contact to decrease the effect of liquid-side diffusion

6 resistance.

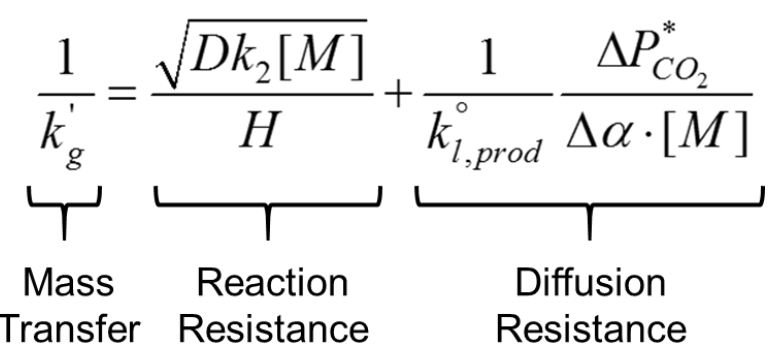

8 While the addition of $\mathbf{1}$ to the capture solutions had no effect on the solution viscosity and only 9 minor effects on MEA surface tension, there is a dramatic increase in the elasticity of MEA upon 10 the addition $\mathbf{1}$. The surfactant-like activity of $\mathbf{1}$ in solutions of MEA make determining the source 11 of any enhancement difficult to isolate, although previous studies have shown the addition of 12 surfactants to capture solutions may cause formation of a single layer film on the surface that 13 blocks $\mathrm{CO}_{2}$ gas diffusion into the liquid and artificially depress the local amine concentration, 14 decreasing overall mass transfer. ${ }^{55}$ However, the constant surface tension and elasticity in solutions 15 of $\mathrm{A} 2 \mathrm{P} / \mathrm{AMP}$ and $\mathrm{A} 2 \mathrm{P} / \mathrm{AMP}+\mathbf{1}$ indicates there is no surfactant-like activity in this solvent blend 16 and any enhancement is likely a result of the catalyst performing as designed. The lack of 17 correlation between the surface properties and capture efficiency in these solutions seems counterintuitive when compared to traditional models of mass transfer in these systems, however as other 19 recent work has shown, caution must be taken when predicting improvements based on 
1 fundamental and idealized laboratory testing methods, as counter-intuitive behavior was observed

2 upon the addition of surfactants to stirred-reactor experiments with a flat gas/liquid interface, ${ }^{55}$

3 much like the wetted-wall experiments here. We previously concluded that although the addition

4 of surfactant lowers surface tension of the solution, it does not serve to promote bulk solvent

5 mixing on its own in these flat interface systems. The lack of bulk mixing is likely exacerbated in

6 the current wetted-wall experiments, due to the lack of mechanical mixing.

7 The lower rich loading of the A2P/AMP makes it an ideal candidate for addition of $\mathbf{1}$ and its

8 increased $\mathrm{CO}_{2}$ absorption properties to both increase the rich loading of the solvent and thereby

9 decrease the overall energy demand of the system. Upon addition of 1 to A2P/AMP, the energy

10 demand was reduced to $187 \mathrm{~kJ} / \mathrm{mol} \mathrm{CO}$, a $21 \%$ reduction. This reduced energy penalty was

11 achieved by decreasing the liquid flowrate from $150 \mathrm{~mL} / \mathrm{min}$ down to $60 \mathrm{~mL} / \mathrm{min}$, while

12 maintaining $90 \% \mathrm{CO}_{2}$ capture and increasing the stripper pressure to $180 \mathrm{kPaa}$ (Table 2). The

13 reduced liquid flowrate achieved upon addition of $\mathbf{1}$ nearly doubled the cyclic capacity of the

14 solvent $\left(0.72\right.$ to $\left.1.37 \mathrm{~mol} \mathrm{CO}_{2} / \mathrm{kg}\right)$. This increased cyclic capacity of the solvent reduces the

15 sensible heat required to heat the solvent and remove the $\mathrm{CO}_{2}$ in the stripper. The increased rich

16 loadings, in addition to the increased cyclic capacity, reduces the energy demand through an

17 increased $\mathrm{CO}_{2} / \mathrm{H}_{2} \mathrm{O}$ (water vapor) ratio in the stripper. This allows for the higher stripper pressures,

18 lowering downstream compression costs, while reducing the energy consumption per unit of $\mathrm{CO}_{2}$

19 produced.

20 4.2. Solvent and Catalyst Behavior. The absorption reactions for any amine based system can be

21 broken into two primary reactions as depicted in Scheme 1. The absorption of $\mathrm{CO}_{2}$ is primarily

22 dictated by the reaction of the primary amine (SC) to form carbamate. The SC reaction generates

23 one mole of proton for each mol of $\mathrm{CO}_{2}$ captured, leading to primary amines being generally 
1 limited on a molar basis to $0.5 \mathrm{CO}_{2}: 1 \mathrm{~N}$. The A2P/AMP solvent utilizes the primary amine A2P as

2 the main component; with AMP added to principally act as a proton receiver (PC) in the solution.

3 The PC serves to free more of the main component, enabling it to react with $\mathrm{CO}_{2}$, and stabilizes

4 the bicarbonate anion at higher carbon loadings. This allows a more carbon rich solution to be

5 achieved. The $\mathrm{pK}_{\mathrm{a}}$ of this proton receiver (AMP) is 9.8, which is higher than that of A2P (9.2)

6 used in solvent. Therefore, the PC preferentially associates with the proton allowing more of the

7 main component to react with $\mathrm{CO}_{2}$. The reaction from the proton receiver to directly produce

8 bicarbonate is prohibitively slower (100x), as is carbamate hydrolysis.

9

\begin{tabular}{|l|}
\hline Absorber \\
$2 \mathrm{SC}+\mathrm{CO}_{2} \longrightarrow[\mathrm{SC}-\mathrm{COO}]^{-}+[\mathrm{SC}-\mathrm{H}]^{+}$ \\
$\mathrm{PC}+[\mathrm{SC}-\mathrm{H}]^{+} \longrightarrow[\mathrm{PC}-\mathrm{H}]^{+}+\mathrm{SC}$
\end{tabular}

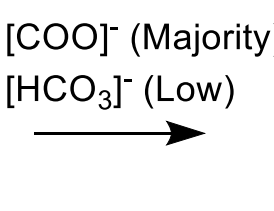

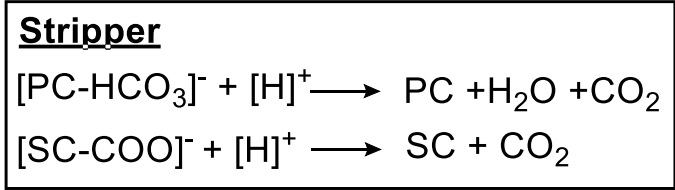

Scheme 1. Schematic for reactions occurring in the $\mathrm{CO}_{2}$ capture cycle. In the illustration: $\mathrm{SC}$ The constituents of the primary amine; PC - The constituents of the proton receiver/hindered amine.

Complex 1 in this work was designed as a carbonic anhydrase (CA) mimic to catalyze $\mathrm{CO}_{2}$ hydration. Thus, it is expected to function similarly to CA's in directly catalyzing the reaction of dissolved $\mathrm{CO}_{2}$ in solution to form bicarbonate and a proton. The proton is then trapped by the PC component (Scheme 1) of the solvent, thereby enhancing the overall mass transfer and capacity.

Due to the nature of the solvent chemistry it can be expected that a greater benefit from the addition of 1 will be observed at higher carbon loadings where $\mathrm{CO}_{2}$ hydration and bicarbonate formation dominates the capture regime.

4.3. Catalyst Cost and Scalability. The economic considerations are imperative when scaling-up a new technology. $\mathbf{1}$ is synthesized in a simple three-step process using all easily acquired commercial reagents, and the product from each step is isolated via filtration without the need for 
1 further purification. The simplistic synthesis methodology attunes itself to already existing large-

2 scale manufacturing processes. We estimate the cost of $\mathbf{1}$ to be $\sim \$ 0.25$ per liter of carbon capture

3 solvent, which roughly equates to $\$ 100$ - $\$ 200$ per megawatt of electricity generated. Cost of any

4 solvent additive is required to be low enough so that it can be treated as a disposable material as it

5 will be removed from the capture system during the thermal solvent reclamation process.

6 Additionally, 1 contains a non-toxic $3 \mathrm{~d}$ metal and is not expected to impart any hazardous waste

7 requirements onto the solvent for disposal.

\section{5. Conclusions}

9 Herein we have demonstrated the development and transition from fundamental and idealized

10 laboratory investigations to CCS process relevant testing of catalyst, $\mathbf{1}$, for the purpose of 11 enhancing overall mass transfer of $\mathrm{CO}_{2}$ into carbon capture solvents for post-combustion acid gas

12 scrubbing technologies and reducing operational costs. Taken together, these studies provide

13 valuable insight into the performance of $\mathbf{1}$, and more importantly considerations that should be

14 taken into account when testing new chemical additives for CCS processes. In laboratory 15 experiments that limit diffusion resistance, such as the $\mathrm{pH}$ drop and breakthrough methods, the 16 performance of $\mathbf{1}$ is as expected. Catalyzing the $\mathrm{CO}_{2}$ hydration reaction increases max flux, 17 especially at higher loadings when the diminishing concentration of free amine and increasing 18 viscosity of the solvent slow $\mathrm{CO}_{2}$ absorption. In the wetted-wall column, when diffusion resistance 19 is significant, the activity of $\mathbf{1}$ is greatly reduced due to the lack of bulk solvent mixing. Process 20 relevant testing of the A2P/AMP +1 solvent was demonstrated in an integrated bench-scale 21 capture unit, and the activity of $\mathbf{1}$ decreases the capture energy of $\mathrm{CO}_{2}$ in an integrated process by $2221 \%$ compared to a $30 \mathrm{wt}$. \% MEA base case by increasing the cyclic capacity and decreasing the 23 sensible heat required for solvent regeneration. 
This work was supported by the U.S. Department of Energy (DE-FE0012926), and the Carbon

Management Research Group (CMRG): Louisville Gas and Electric \& Kentucky Utilities, Duke

Energy, Kentucky Department for Energy Development and Independence, and the Electric Power

Research Institute, Inc.

\section{References}

1. (a) Standards of Performance for Greenhouse Gas Emissions From New Stationary Sources: Electric Utility Generating Units, Environmental Protection Agency (Jan. 8, 2014). (b) Carbon Pollution Emission Guidelines for Existing Stationary Sources: Electric Utility Generating Units, Environmental Protection Agency (June 2, 2014).

2. $\quad$ Liang, Z. W.; Rongwong, W.; Liu, H. L.; Fu, K. Y.; Gao, H. X.; Cao, F.; Zhang, R.; Sema, T.; Henni, A.; Sumon, K.; Nath, D.; Gelowitz, D.; Srisang, W.; Saiwan, C.; Benamor, A.; Al-Marri, M.; Shi, H. C.; Supap, T.; Chan, C.; Zhou, Q.; Abu-Zahra, M.; Wilson, M.; Olson, W.; Idem, R.; Tontiwachwuthikul, P., Recent progress and new developments in post-combustion carbon-capture technology with amine based solvents. Int. J. Greenhouse Gas Control 2015, 40, 26-54.

3. Cost and Performance Baseline for Fossil Energy Plants - Volume 1: Bituminous Coal and Natural Gas to Electricity (Rev 2, November 2010).

4. Lu, Y.; Ye, X. H.; Zhang, Z. H.; Khodayari, A.; Djukadi, T., Development of a Carbonate AbsorptionBased Process for Post-Combustion $\mathrm{CO}_{2}$ Capture: the Role of Biocatalyst to Promote $\mathrm{CO}_{2}$ Absorption Rate. Energy Procedia 2011, 4, 1286-1293.

5. Vinoba, M.; Bhagiyalakshmi, M.; Grace, A. N.; Kim, D. H.; Yoon, Y.; Nam, S. C.; Baek, I. H.; Jeong, S. K., Carbonic Anhydrase Promotes the Absorption Rate of $\mathrm{CO}_{2}$ in Post-Combustion Processes. J. Phys. Chem. B 2013, 117 (18), 5683-5690.

6. Penders-van Elk, N. J. M. C.; Hamborg, E. S.; Huttenhuis, P. J. G.; Fradette, S.; Carley, J. A.; Versteeg, G. F., Kinetics of absorption of carbon dioxide in aqueous amine and carbonate solutions with carbonic anhydrase. Int. J. Greenhouse Gas Control 2013, 12, 259-268.

7. Penders-van Elk, N. J. M. C.; Fradette, S.; Versteeg, G. F., Effect of pKa on the kinetics of carbon dioxide absorption in aqueous alkanolamine solutions containing carbonic anhydrase at $298 \mathrm{~K}$. Chem. Eng. J. 2015, 259, 682-691.

8. Li, L.; Voice, A. K.; Li, H.; Namjoshi, O.; Nguyen, T.; Du, Y.; Rochelle, G. T., Amine blends using concentrated piperazine. Energy Procedia 2013, 37, 353-369.

9. Voice, A. K.; Vevelstad, S. J.; Chen, X.; Nguyen, T.; Rochelle, G. T., Aqueous 3(methylamino)propylamine for $\mathrm{CO}_{2}$ capture. Int. J. Greenhouse Gas Control 2013, 15, 70-77.

10. Sherman, B.; Chen, X.; Nguyen, T.; Xu, Q.; Rafique, H.; Freeman, S. A.; Voice, A. K.; Rochelle, G. T., Carbon Capture with 4 M Piperazine/4 M 2-Methylpiperazine. Energy Procedia 2013, 37, 436-447.

11. Lin, P. H.; Wong, D. S. H., Carbon dioxide capture and regeneration with amine/alcohol/water blends. Int. J. Greenhouse Gas Control 2014, 26, 69-75.

12. Shi, H. C.; Naami, A.; Idem, R.; Tontiwachwuthikul, P., Catalytic and non catalytic solvent regeneration during absorption-based $\mathrm{CO}_{2}$ capture with single and blended reactive amine solvents. Int. J. Greenhouse Gas Control 2014, 26, 39-50. 
13. Adeosun, A.; Abu-Zahra, M. R. M., Evaluation of amine-blend solvent systems for $\mathrm{CO}_{2}$ postcombustion capture applications. Energy Procedia 2013, 37, 211-218.

14. Aroonwilas, A.; Veawab, A., Integration of $\mathrm{CO}_{2}$ capture unit using single- and blended-amines into supercritical coal-fired power plants: Implications for emission and energy management. Int. J. Greenhouse Gas Control 2007, 1 (2), 143-150.

15. Tsai, R. E.; Schultheiss, P.; Kettner, A.; Lewis, J. C.; Seibert, A. F.; Eldridge, R. B.; Rochelle, G. T., Influence of surface tension on effective packing area. Ind. Eng. Chem. Res. 2008, 47 (4), 1253-1260.

16. Tsai, R. E.; Seibert, A. F.; Eldridge, R. B.; Rochelle, G. T., A Dimensionless Model for Predicting the Mass-Transfer Area of Structured Packing. AIChE J. 2011, 57 (5), 1173-1184.

17. Floyd, W. C., III; Baker, S. E.; Valdez, C. A.; Stolaroff, J. K.; Bearinger, J. P.; Satcher, J. H., Jr.; Aines, R. D., Evaluation of a carbonic anhydrase mimic for industrial carbon capture. Environ. Sci. Technol. 2013, 47 (17), 10049-55.

18. Koziol, L.; Valdez, C. A.; Baker, S. E.; Lau, E. Y.; Floyd, W. C.; Wong, S. E.; Satcher, J. H.; Lightstone, F. C.; Aines, R. D., Toward a Small Molecule, Biomimetic Carbonic Anhydrase Model: Theoretical and Experimental Investigations of a Panel of Zinc(II) Aza-Macrocyclic Catalysts. Inorg. Chem. 2012, 51 (12), 6803-6812.

19. Zhang, X. P.; Vaneldik, R.; Koike, T.; Kimura, E., Kinetics and Mechanism of the Hydration of $\mathrm{CO}_{2}$ and Dehydration of $\mathrm{HCO}_{3}{ }^{-}$Catalyzed by a $\mathrm{Zn}$ (II) Complex of 1,5,9-Triazacyclododecane as a Model for Carbonic Anhydrase. Inorg. Chem. 1993, 32 (25), 5749-5755.

20. Zhang, X. P.; Vaneldik, R., A Functional Model for Carbonic Anhydrase - Thermodynamic and Kinetic Study of a Tetraazacyclododecane Complex of Zinc(II). Inorg. Chem. 1995, 34 (22), 5606-5614.

21. Liang, Z.; Idem, R.; Tontiwachwuthikul, P.; Yu, F.; Liu, H.; Rongwong, W., Experimental study on the solvent regeneration of a $\mathrm{CO}_{2}$-loaded MEA solution using single and hybrid solid acid catalysts. AIChE J. 2016, 62 (3), 753-765.

22. Evans, M. G.; Polanyi, M., Further considerations on the thermodynamics of chemical equilibria and reaction rates. Trans. Faraday Soc. 1936, 32, 1333-1360.

23. Nwaoha, C.; Idem, R.; Supap, T.; Saiwan, C.; Tontiwachwuthikul, P.; Rongwong, W.; Al-Marri, M. J.; Benamor, A., Heat duty, heat of absorption, sensible heat and heat of vaporization of 2-Amino-2Methyl-1-Propanol (AMP), Piperazine (PZ) and Monoethanolamine (MEA) tri-solvent blend for carbon dioxide $\left(\mathrm{CO}_{2}\right)$ capture. Chem. Eng. Sci.

24. Huang, Q. Z.; Bhatnagar, S.; Remias, J. E.; Selegue, J. P.; Liu, K. L., Thermal degradation of amino acid salts in $\mathrm{CO}_{2}$ capture. Int. J. Greenhouse Gas Control 2013, 19, 243-250.

25. Wang, T. L.; Jens, K. J., Oxidative Degradation of AMP/MEA Blends for Post-combustion $\mathrm{CO}_{2}$ Capture. Energy Procedia 2013, 37, 306-313.

26. Voice, A. K.; Hill, A.; Fine, N. A.; Rochelle, G. T., Nitrosamine formation and mitigation in blended amines for $\mathrm{CO}_{2}$ capture. Int. J. Greenhouse Gas Control 2015, 39, 329-334.

27. Kelsey, R. A.; Miller, D. A.; Parkin, S. R.; Liu, K.; Remias, J. E.; Yang, Y.; Lightstone, F. C.; Liu, K. L.; Lippert, C. A.; Odom, S. A., Carbonic anhydrase mimics for enhanced $\mathrm{CO}_{2}$ absorption in an amine-based capture solvent. Dalton Trans. 2016, 45 (1), 324-333.

28. Lippert, C. A.; Widger, L. R.; Sarma, M.; Liu, K. L., Catalyst Development for Rate Enhanced Acid Gas $\left(\mathrm{CO}_{2}\right)$ Scrubbing. Energy Procedia 2014, 63, 273-278.

29. Lippert, C. A.; Liu, K.; Sarma, M.; Parkin, S. R.; Remias, J. E.; Brandewie, C. M.; Odom, S. A.; Liu, K. L., Improving carbon capture from power plant emissions with zinc- and cobalt-based catalysts. Catal. Sci. Technol. 2014, 4 (10), 3620-3625.

30. Bond, G. M.; Stringer, J.; Brandvold, D. K.; Simsek, F. A.; Medina, M. G.; Egeland, G., Development of integrated system for biomimetic $\mathrm{CO}_{2}$ sequestration using the enzyme carbonic anhydrase. Energy Fuels 2001, 15 (2), 309-316. 
31. Liu, K.; Jinka, K. M.; Remias, J. E.; Liu, K. L., Absorption of Carbon Dioxide in Aqueous Morpholine Solutions. Ind. Eng. Chem. Res. 2013, 52 (45), 15932-15938.

32. Delaney, M. S.; Reddy, D.; Wessling, R. A., Oxygen/nitrogen transport in glassy polymers with oxygen-binding pendent groups. Journal of Membrane Science 1990, 49 (1), 15-36.

33. Rao, A. B.; Rubin, E. S., A Technical, Economic, and Environmental Assessment of Amine-Based $\mathrm{CO}_{2}$ Capture Technology for Power Plant Greenhouse Gas Control. Environ. Sci. Technol. 2002, 36 (20), 4467-4475.

34. Gouedard, C.; Picq, D.; Launay, F.; Carrette, P. L., Amine degradation in $\mathrm{CO}_{2}$ capture. I. A review. Int. J. Greenhouse Gas Control 2012, 10, 244-270.

35. Conway, W.; Wang, X.; Fernandes, D.; Burns, R.; Lawrance, G.; Puxty, G.; Maeder, M., Toward the understanding of chemical absorption processes for post-combustion capture of carbon dioxide: electronic and steric considerations from the kinetics of reactions of $\mathrm{CO}_{2}(\mathrm{aq})$ with sterically hindered amines. Environ. Sci. Technol. 2013, 47 (2), 1163-9.

36. Conway, W.; Wang, X.; Fernandes, D.; Burns, R.; Lawrance, G.; Puxty, G.; Maeder, M., Comprehensive kinetic and thermodynamic study of the reactions of $\mathrm{CO}_{2}(\mathrm{aq})$ and $\mathrm{HCO}_{3}{ }^{-}$with monoethanolamine (MEA) in aqueous solution. J. Phys. Chem. A 2011, 115 (50), 14340-9.

37. McCann, N.; Phan, D.; Wang, X.; Conway, W.; Burns, R.; Attalla, M.; Puxty, G.; Maeder, M., Kinetics and mechanism of carbamate formation from $\mathrm{CO}_{2}(\mathrm{aq})$, carbonate species, and monoethanolamine in aqueous solution. J. Phys. Chem. A 2009, 113 (17), 5022-9.

38. Benamor, A.; Aroua, M. K., An Experimental Investigation on the rate of $\mathrm{CO}_{2}$ Absorption into aqueous methyldiethanolamine solutions. Korean J. Chem. Eng. 2007, 24 (1), 16-23.

39. Vaidya, P. D.; Kenig, E. Y., $\mathrm{CO}_{2}$-Alkanolamine Reaction Kinetics. Chem. Eng. Technol. 2007, 30 (11), $1467-1474$.

40. Xu, S.; Wang, Y. W.; Otto, F. D.; Mather, A. E., Kinetics of the reaction of carbon dioxide with 2amino-2-methyl-1-propanol solutions. Chem. Eng. Sci. 1996, 51 (6), 841-850.

41. Sami, H. A.; Merchant, S. Q.; Fahim, M. A., Reaction kinetics of some secondary alkanolamines with carbon dioxide in aqueous solutions by stopped flow technique. Sep. Purif. Technol. 2002, 27, 121136.

42. Ume, C. S.; Ozturk, M. C.; Alper, E., Kinetics of $\mathrm{CO}_{2}$ absorption by a blended aqueous amine solution. Chem. Eng. Technol. 2012, 35 (3), 464-468.

43. Penny, D. E.; Ritter, T. J., Kinetic study of the reaction between carbon dioxide and primary amines. J. Chem. Soc., Faraday Trans. 1 1983, 79 (9), 2103-2109.

44. Barth, D.; Tondre, C.; Delpuech, J. J., Stopped-flow investigations of the reaction kinetics of carbon dioxide with some primary and secondary alkanolamines in aqueous solutions. Int. J. Chem. Kinet. 1986, 18 (4), 445-457.

45. Crooks, J. E.; Donnellan, J. P., Kinetics and mechanism of the reaction between carbon dioxide and amines in aqueous solution. J. Chem. Soc., Perkin Trans. 2 1989, (4), 331-333.

46. Alper, E., Reaction mechanism and kinetics of aqueous solutions of 2-amino-2-methyl-1-propanol and carbon dioxide. Ind. Eng. Chem. Res. 1990, 29 (8), 1725-1728.

47. Laddha, S. S.; Danckwerts, P. V., Reaction of $\mathrm{CO}_{2}$ with ethanolamines: kinetics from gasabsorption. Chem. Eng. Sci. 1981, 36 (3), 479-482.

48. Hikita, H.; Asai, S.; Ishikawa, H.; Honda, M., The kinetics of reactions of carbon dioxide with monoethanolamine, diethanolamine and triethanolamine by a rapid mixing method. The Chemical Engineering Journal 1977, 13 (1), 7-12.

49. Ali, S. H.; Merchant, S. Q.; Fahim, M. A., Reaction kinetics of some secondary alkanolamines with carbon dioxide in aqueous solutions by stopped flow technique. Sep. Purif. Technol. 2002, 27 (2), 121-136. 
1 50. Henni, A.; Li, J.; Tontiwachwuthikul, P., Reaction Kinetics of $\mathrm{CO}_{2}$ in Aqueous 1-Amino-2-Propanol, 2 3-Amino-1-Propanol, and Dimethylmonoethanolamine Solutions in the Temperature Range of 298-313 K 3 Using the Stopped-Flow Technique. Ind. Eng. Chem. Res. 2008, 47 (7), 2213-2220.

4 51. Kohl, A.; Nielsen, R. Gas Purification, 5th ed.; Gulf Publishing Co.: Houston, TX, 1997.

5 52. Aouini, I.; Ledoux, A.; Estel, L.; Mary, S.; Grimaud, J.; Valognes, B., Study of carbon dioxide capture 6 from industrial incinerator flue gas on a laboratory scale pilot. Energy Procedia 2011, 4, 1729-1736.

7 53. Gunasekaran, P.; Veawab, A.; Aroonwilas, A., Corrosivity of Single and Blended Amines in $\mathrm{CO}_{2}$ 8 Capture Process. Energy Procedia 2013, 37, 2094-2099.

$9 \quad 54 . \quad$ Song, D.; Seibert, A. F.; Rochelle, G. T., Effect of Liquid Viscosity on the Liquid Phase Mass Transfer 10 Coefficient of Packing. Energy Procedia 2014, 63, 1268-1286.

11 55. Bryant, J. J.; Lippert, C.; Qi, G.; Liu, K.; Mannel, D. S.; Liu, K., Enhanced Carbon Capture through 12 Incorporation of Surfactant Additives. Ind. Eng. Chem. Res. 2016, 55 (27), 7456-7461.

13 56. Georgieva, D.; Cagna, A.; Langevin, D., Link between surface elasticity and foam stability. Soft 14 Matter 2009, 5 (10), 2063-2071.

15 57. Maddox, R. N. Gas and Liquid Sweetening In Gas Conditioning and Processing, Third Edition; 16 Campbell, J. M., Ed.; Campbell Petroleum Series: Norman, OK, 1994.

17 58. Huang, Q. Z.; Thompson, J.; Bhatnagar, S.; Chandan, P.; Remias, J. E.; Selegue, J. P.; Liu, K. L., Impact 18 of Flue Gas Contaminants on Monoethanolamine Thermal Degradation. Ind. Eng. Chem. Res. 2014, 53 (2), 19 553-563. 